\title{
Occurrence and risk assessment of multiple classes of antibiotics in urban canals and lakes in Hanoi, Vietnam
}

Ngoc Han Tran a, b, *, Lan Hoang c, Long Duc Nghiem d, Nu My Ha Nguyen e,f, Huu Hao Ngo d, Wenshan Guo d, Quang Thang Trinh b, Nam Hai Mai g, Huiting Chen a, Dinh Duc Nguyen h, Thi Thao Ta e, Karina Yew-Hoong Gin a, i*

a NUS Environmental Research Institute, National University of Singapore, 1-Create Way, \#15-02 Create Tower, Singapore 138602, Singapore.

b Institute of Research and Development, Duy Tan University, Da Nang 550000, Viet Nam.

c Advanced Institute for Science and Technology, Hanoi University of Science and Technology, 1 Dai Co Viet, Hanoi, Vietnam.

d Centre for Technology in Water and Wastewater, School of Civil and Environmental Engineering, University of Technology Sydney, Sydney, NWS 2007, Australia

e Faculty of Chemistry, Hanoi University of Science, 1 Le Thanh Tong, Hanoi, Viet Nam.

Institute of Continuing Education, Ha Tinh University, No. 447, Road-26/3, Dai Nai, Ha Tinh, Viet Nam

g School of Medicine, University of California San Francisco, 1001 Potrero Avenue, BIdg. 30, SFGH, CA 94110

h Department of Environmental Energy Engineering, Kyonggi University, Suwon 16227, Republic of Korea

i Department of Civil and Environmental Engineering, National University of Singapore, 1 Engineering Drive 2, Singapore 117576, Singapore.

* Corresponding authors

Email addresses: ceeginyh@nus.edu.sg(K.Y.H.Gin); eritnh@nus.edu.sg (N.H.Tran).

\begin{abstract}
Very little information on the occurrence and risk assessment of antibiotics in the aquatic environment is reported for Vietnam, where antibiotics are assumed to be omnipresent in urban canals and lakes at high concentrations due to the easy accessibility of antibiotics without doctor prescription. This study provides comprehensive analysis of the occurrence of 23 antibiotics in urban canals (To Lich and Kim Nguu) and lakes (West Lake, Hoan Kiem, and Yen So) in Hanoi, Vietnam. Of these 23 antibiotics, 18 were detected in urban canals at above $67.9 \%$ detection frequency (DF). The concentrations of detected antibiotics were in the range from below quantification limit (MQL) to almost 50,000 ng/L, depending on the compound and sampling site. In urban canals, median concentration of amoxicillin, erythromycin, and sulfamethoxazole
\end{abstract}


was $>1000 \mathrm{ng} / \mathrm{L}$ while other antibiotics such as ampicillin, chloramphenicol, clindamycin, sulfamethazine, tetracycline, tylosin and vancomycin were detected at median concentrations of $<100 \mathrm{ng} / \mathrm{L}$. Similarly, 16 target antibiotics were also detected in urban lakes. Macrolides (azithromycin, clarithromycin, and erythromycin- $\mathrm{H}_{2} \mathrm{O}$ ), fluoroquinolones (enrofloxacin and ofloxacin), lincosamides (clindamycin and lincomycin), and trimethoprim were ubiquitously detected in urban lakes (DF=100\%). In this study, potential risks of antibiotics in the investigated urban canals and lakes were assessed based on the predicted no-effect concentration (PNEC) from the existing literature for antibiotic resistance selection (PNEC $\mathrm{ARM}_{\text {) }}$ and ecological toxicity to aquatic organisms (PNEC $\left.\mathrm{Ecotox}_{\mathrm{x}}\right)$ Ampicillin, amoxicillin, azithromycin, ciprofloxacin, clarithromycin, enrofloxacin, erythromycin, ofloxacin, tetracycline, and trimethoprim were found in the investigated urban canals at concentrations exceeding their $\mathrm{PNEC}_{\mathrm{ARM}}$ and $\mathrm{PNEC}_{\mathrm{Ecotox}}$. Similarly, most of the target antibiotics (i.e. amoxicillin, ciprofloxacin, clarithromycin, clindamycin, enrofloxacin, erythromycin, lincomycin, ofloxacin, sulfamethoxazole, tetracycline, trimethoprim and tylosin) were found in the investigated urban lakes at concentrations close to or exceeding PNEC $_{\text {Ecotox }}$ for aquatic organisms. Further investigations on the occurrence and fate of antibiotic residues and antibiotic resistant bacteria (ARB) and antibiotic resistance genes (ARGs) in surface waters are recommended

Keywords: Antibiotics; Antibiotic resistance bacteria; Ecological toxicity; Environmental risk assessment; Surface water; Wastewater.

\section{Introduction}

Antibiotics are routinely used in both human and veterinary medicine to prevent and treat microbial infections (Kummerer, 2009; Blair et al., 2015). In addition, they are also widely used as growth promoters in livestock/poultry animals and aquaculture farms (Kümmerer and Henninger, 2003; Kummerer, 2009). Due to incomplete metabolism in humans or animals, 50-90\% of the administrated antibiotics are excreted via urine and feces as a mixture of parent and metabolite forms (Kummerer, 2009; Le-Minh et al., 2010; Zonja et al., 2016), resulting in frequent detection in wastewater and receiving surface water bodies (Hirsch et al., 1999; Le-Minh et al., 
2010; Tran et al., 2018). In fact, antibiotic residues enter into the aquatic environment via a number of routes, including (i) the direct discharge of untreated sewage from residential areas (Al Aukidy et al., 2012; Verlicchi et al., 2012) hospitals (Duong et al., 2008; Kosma et al., 2010; Verlicchi et al., 2010; Al Aukidy et al., 2014), poultry and meat processing manufacturers, and household pets; (ii) discharge of treated wastewater effluents from wastewater treatment plants (Le-Minh et al., 2010; Luo et al., 2014; Tran et al., 2016b; Tran et al., 2018); (iii) surface runoff; (iv) infiltration from manure-amended agricultural lands (Kreuzinger et al., 2004; Cha and Cupples, 2009).

In recent decades, the widespread occurrence of antibiotics in the aquatic environment has gained increasing attention due to the proven or potential adverse effects on aquatic ecosystems and human health (Andreozzi et al., 2004; Knapp et al., 2010; Al Aukidy et al., 2012; Drury et al., 2013). A major concern associated with the occurrence of antibiotics in the environment is the development of antibiotic resistance bacteria (ARB) and the proliferation of antibiotic resistance genes (ARGs) (Kim and Aga, 2007; Rizzo et al., 2013; Blair et al., 2015). Previous studies found the frequent occurrence of ARB and ARGs in wastewater and surface waters (Jong et al., 2018; Lamba et al., 2018; Le et al., 2018). In addition, these antibiotics can also be toxic to sensitive aquatic organisms at concentration reported in the literature (Halling-Sørensen et al., 2000; Isidori et al., 2005; Ando et al., 2007; Richardson and Ternes, 2011; Minguez et al., 2016).

The occurrence of antibiotics in the aquatic environment has been well documented in many developed countries in North America, Europe, and East Asia. By contrast, very little information on the distribution of antibiotics is available for low- and lower middle-income countries, where the application of antibiotics for medical and veterinary purposes is very significant (Duong et al., 2008; Phan et al., 2011). A notable example is Vietnam. With a population exceeding 96 million, Vietnam is the world's $15^{\text {th }}$ most populous country. The demand for antibiotics has increased rapidly as a result of high economic growth, rising income per capita, higher urbanization as well as ageing population (Nguyen et al., 2013). In earlier studies, Nguyen et al. (2013) and Nga et al. (2014) reported that the most commonly sold antibiotics were the second- and third-generation 
cephalosporins, followed by macrolides, azalides and fluoroquinolones. It is noteworthy that relatively new injectable antibiotics (e.g., carbapenems) are sold in hospitals, while banned antibiotics (e.g. chloramphenicol) are still obtained in retail pharmacies (Nguyen et al., 2013). Unlike developed countries, antibiotics and other pharmaceuticals in Vietnam can be readily obtained over-the-counter without doctor prescription (Duong et al., 2008; Tran et al., 2018) and self-medication is a common practice (Nguyen et al., 2013; Hoai and Dang, 2017). For these reasons, the emission, occurrence and environmental risks of antibiotics in the environment in Vietnam have raised serious concerns. In an earlier study, for example, it was reported that Vietnam had the highest prevalence of penicillin-resistant (71.4\%) and erythromycin resistant (91.2\%) Streptococcus pneumoniae (Song et al., 2004).

Despite being a country with high antibiotics consumption, information on the occurrence of antibiotics in the aquatic environment of Vietnam is still very limited (Le and Munekage, 2004; Duong et al., 2008; Phan et al., 2011; Thai et al., 2018). A major limitation of the few earlier studies in Vietnam is the focus only on wastewater compartment, while information regarding the occurrence of antibiotics in surface water (i.e. lakes and rivers) has not been investigated. Duong et al. (2008) investigated the occurrence of two fluoroquinolone antibiotics (i.e. ciprofloxacin and norfloxacin) in hospital wastewater samples. The information on the distribution of antibiotics in other environmental compartments (i.e. municipal wastewater and surface water) was not available in Duong et al. (2008). Phan et al. (2011) focused on the determination of selected antibiotics (i.e. sulfonamides, macrolides and trimethoprim) in wastewater samples from urban canals and fish/pig farms. Thai et al. (2018) measured the occurrence of several antibiotics in effluents from a hospital, pharmaceutical manufacturing plant and aquaculture farming. In addition, another drawback of these earlier studies is the lack of isotopically labeled internal standards (ILISs) for compensating and correcting the losses of target antibiotics during sample preparation and matrix effects during LC-MS/MS analyses. For example, the losses of target antibiotics throughout sample preparation, especially in terms of the losses by degradation during transportation from Vietnam to Japan in a previous study by Phan et 
al. (2011), were not compensated and corrected due to the lack of ILISs. In a recent study by Thai et al. (2018), the use of trimethoprim ${ }^{-13} \mathrm{C}_{3}$ as a surrogate and internal standard could be inefficient for antibiotics belonging to beta-lactams, macrolides, sulfonamides and fluoroquinolones due to the differences in physicochemical properties (i.e. $\log \mathrm{K}_{\mathrm{ow}}$ and $\mathrm{pK}_{\mathrm{a}}$ ), chemical structure, extraction efficacy, and chromatographic retention time between trimethoprim- ${ }^{13} \mathrm{C}_{3}$ and other investigated antibiotics. For these reasons, the monitoring data of antibiotics in the environmental water samples in those studies (Duong et al., 2008; Phan et al., 2011; Thai et al., 2018) could be underestimated or overestimated.

To fill the existing knowledge gap, therefore, the first objective of this study was to provide quantitative information on the occurrence of antibiotics in surface waters (i.e. urban lakes), especially regarding the antibiotic classes with possible public health risks for antibiotic resistance selection, such as beta-lactams (Graham et al., 2016; Jong et al., 2018; Lamba et al., 2018), lincosamides (Koike et al., 2010), tetracyclines (Knapp et al., 2010; Gao et al., 2012), glycopeptides (Schwartz et al., 2003), amphenicols (Hanna et al., 2018), sulfonamides (Le et al., 2018), fluoroquinolones (Rodriguez-Mozaz et al., 2015), and macrolides (Koike et al., 2010). Occurrence data of antibiotics in urban canals and lakes of this study were compared to those in other countries. The second objective was to evaluate the possible risks of antibiotics in urban canals and lakes based on their measured environmental concentrations (MEC) and predicted noeffect concentration for antibiotic resistance selection $\left(\mathrm{PNEC}_{\mathrm{ARM}}\right)$ and ecological toxicity to aquatic ecosystems ( $\left.\mathrm{PNEC}_{\mathrm{Ecotox}}\right)$. To the best of our knowledge, to date, little information on possible risks of antibiotics for resistance selection based on $\mathrm{MEC}$ and $\mathrm{PNEC}_{\mathrm{ARM}}$ is reported for the nonclinical environment.

\section{Materials and methods}

\subsection{Target antibiotics, chemical reagents and solvents}

In this study, 23 target antibiotics (ABs) belonging to nine different classes were investigated. They include: 
[1] $\beta$-lactams: ceftazidime [CFZ], meropenem [MER], ampicillin [AMP], cefixime [CFEX] and amoxicillin [AMX].

[2] Fluoroquinolones: ciprofloxacin [CIPX], enrofloxacin [ENFLX], and ofloxacin [OFLX]

[3] Lincosamides: lincomycin [LIN] and clindamycin [CLI].

[4] Macrolides: erythromycin [ERY], azithromycin [AZT], clarithromycin [CLAR], and tylosin [TYL].

[5] Sulfonamides: sulfamethazine [SMZ] and sulfamethoxazole [SMX].

[6] Reductase inhibitor: trimethoprim [TMP].

[7] Tetracyclines: tetracycline [TET], minocycline [MIN], chlortetracycline [CTC], and oxytetracycline [OXY].

[8] Glycopeptide: vancomycin [VCM].

[9] Amphenicol: chloramphenicol [CAP].

The physicochemical properties of the target ABs are presented in Table A.1 (Supplementary Information). All the target $\mathrm{ABs}$ as well as other chemical reagents/solvents are of analytical grade (>99\% in purity) and were purchased from Sigma-Aldrich (Sigma-Aldrich, Singapore). In this study, $13{ }^{2} \mathrm{H}$-isotope labelled internal/surrogate standards (ILISs) were purchased from Toronto Research Chemicals (Toronto, Canada), including ceftazidime- $\mathrm{d}_{5}$ [CFZ- $\left.\mathrm{d}_{5}\right]$, meropenem$\mathrm{d}_{6} \quad\left[\right.$ MER- $\left.\mathrm{d}_{6}\right]$, ciprofloxacin- $\mathrm{d}_{8} \quad\left[\right.$ CIPX- $\left.\mathrm{d}_{8}\right]$, lincomycin- $\mathrm{d}_{3} \quad$ [LIN- $\left.\mathrm{d}_{3}\right]$, clindamycin- $\mathrm{d}_{3} \quad\left[\right.$ CLI- $\left.\mathrm{d}_{3}\right]$, azithromycin- $\mathrm{d}_{3} \quad\left[\right.$ AZT- $\left.\mathrm{d}_{3}\right], \quad$ clarithromycin- $\mathrm{d}_{3} \quad$ [CLAR- $\left.\mathrm{d}_{3}\right]$, erythromycin- $\mathrm{d}_{6} \quad$ [ERY- $\left.\mathrm{d}_{6}\right]$, sulfamethazine- $\mathrm{d}_{4} \quad\left[\mathrm{SMZ}-\mathrm{d}_{4}\right], \quad$ sulfamethoxazole- $\mathrm{d}_{4} \quad\left[\mathrm{SMX}-\mathrm{d}_{4}\right]$, trimethoprim- $\mathrm{d}_{3} \quad\left[\mathrm{TMP}-\mathrm{d}_{3}\right]$, tetracycline- $\mathrm{d}_{6}\left[\right.$ TET- $\left.\mathrm{d}_{6}\right]$, and chloramphenicol- $\mathrm{d}_{5}\left[\right.$ CAP- $\left.\mathrm{d}_{5}\right]$.

\subsection{Study area and sample collections}

This study was conducted in Hanoi, which is the capital of Vietnam and the nation's second biggest city with a population of over 7.6 million inhabitants. Water consumption per person per day in Hanoi is estimated at approximately 150 liters (Tran et al., 2014). The occurrence of antibiotics in open-air urban canals was investigated at To Lich (TL) and Kim Nguu (KN) rivers. These two canals were once distributaries of the Red river. In more recent years, due to 
urbanisation, they have been fortified with concrete embankment to carry household wastewater, hospital effluents, and stormwater runoff away from the city (Huong et al., 2010). To investigate the occurrence of antibiotics in urban lakes, three freshwater lakes in Hanoi including Hoan Kiem (HK), West Lake (WL), and Yen So (YS) were selected for this study. West Lake is the largest lake in Hanoi with a shore length of about $17 \mathrm{~km}$ and 500 hectare in area. West Lake, Yen So, and Hoan Kiem receive urban stormwater runoff from surrounding residential areas. Due to urbanisation, it is widely acknowledged that untreated wastewater can also enter West Lake. In addition to a small portion of untreated wastewater, Yen So lake also receives secondary treated effluent from the Yen So wastewater treatment plant. HK only receives urban stormwater runoff.

This study consisted of five sampling campaigns (November 2016, January 2017, May 2017, August 2018, and December 2018) at different sampling locations as shown in Fig. 1 and Table A.2 (Supplementary Information). Briefly, urban canal samples were taken at the following sampling points, TL1 $(n=3)$, TL2 $(n=3)$, TL3 $(n=3)$, TL4 $(n=3)$, TL5 $(n=2)$, KN1 $(n=2)$, KN2 $(n=2)$, KN3 $(n=2), \operatorname{KN} 4(n=2), \operatorname{KN} 5(n=2), \operatorname{KN} 6(n=2)$, and KN7 $(n=2)$, located in TL and KN canals (Fig. 1). Urban canal samples were collected at the central portion of the investigated canals with a sampling depth of about $20-30 \mathrm{~cm}$. Urban lake samples were collected at the sampling points, WL1 $(n=3)$, WL2 $(n=3)$, WL3 $(n=3)$, WL4 $(n=3), \operatorname{HK1}(n=2), \operatorname{HK} 2(n=2)$, and HK3 $(n=2)$, YS1 $(n=2)$, YS2 $(n=3)$, and YS3 $(n=2)$, which are situated in the investigated urban lakes (WL, HK and YS) as shown in Fig. 1. It was noted that urban lake water samples were taken at the locations with their distance from shoreline about $1.5 \mathrm{~m}$.

All water samples were collected as grab samples, filled in 500-mL bottles, and immediately carried to the laboratory. Once samples arrived at the laboratory, the samples were filtered using $1.2 \mu \mathrm{m}$ glass fiber filters (GF/C, Whatman, UK), followed by $0.45 \mu \mathrm{m}$ membrane filters (PALL, corporation, US). Subsequently, the filtrate samples were spiked with a constant amount of ILISs (100 ng). The addition of ILISs (i.e. CFZ- $\mathrm{d}_{5}$, MER- $\mathrm{d}_{6}$, CIPX- $\mathrm{d}_{8}, \mathrm{LIN}-\mathrm{d}_{3}$, CLI- $\mathrm{d}_{3}$, AZT- $\mathrm{d}_{3}$, CLAR- $\mathrm{d}_{3}$, ERY$\mathrm{d}_{6}, \mathrm{SMZ}-\mathrm{d}_{4}, \mathrm{SMX}-\mathrm{d}_{4}$, TMP- $\mathrm{d}_{3}$, TET- $\mathrm{d}_{6}$, and CAP- $\mathrm{d}_{5}$,) to the filtered water samples before storage at 4 
${ }^{\circ} \mathrm{C}$ can correct for any degradation and the loss of target analytes during the storage and sample treatment.

\subsection{Chemical analysis}

Concentrations of the 23 target $\mathrm{ABs}$ in aqueous phase of the collected urban canal and lake water samples were analyzed using solid phase extraction (SPE) coupled with ultrahigh performance liquid chromatography-tandem mass spectrometry (UPLC-MS/MS) and isotope dilution as reported by (Tran et al., 2016a) with slight modifications. Briefly, the SPE cartridges used in this study were Chromabond ${ }^{\circledR}$ HR-X $(500 \mathrm{mg}, 6 \mathrm{~mL})$, and SPE was carried out at sample pH of 3.0. Firstly, the SPE cartridges were preconditioned with $5 \mathrm{~mL}$ of methanol, followed by $5 \mathrm{~mL}$ of acidified Milli $\mathrm{Q}$ water $(\mathrm{pH}$ 3) at a flow rate of $3 \mathrm{~mL} / \mathrm{min}$. Subsequently, $200 \mathrm{~mL}$ of urban canal water samples or $300 \mathrm{~mL}$ of urban lake water samples, which were earlier spiked with a constant amount of ILISs (100 ng) and acidified to pH 3.0, were loaded onto the cartridges at a flow rate of $5 \mathrm{~mL} / \mathrm{min}$. After all water samples were passed through SPE cartridges, the cartridges were rinsed with $5 \mathrm{~mL}$ of acidified Milli-Q water ( $\mathrm{pH}$ 3.0) in order to remove weakly bound impurities and $\mathrm{Na}_{4}$ EDTA. Before elution, the SPE cartridges were dried for 30 min under vacuum. Elution of the target analytes from the SPE cartridges were performed using $5 \mathrm{~mL}$ of methanol at a flow rate of $1 \mathrm{~mL} / \mathrm{min}$. The resulting extracts containing the target analytes were dried under a gentle stream of nitrogen at $35^{\circ} \mathrm{C}$. The dried extracts were finally dissolved again with $1 \mathrm{~mL}$ of a mixture of methanol and Milli-Q water (50:50, v/v). The final aliquots were transferred into $2 \mathrm{~mL}$ amber vials and stored at $-20^{\circ} \mathrm{C}$ until UHPLC-MS/MS analyses.

The UPLC-MS/MS used here was an Agilent 1290 Infinity LC coupled to an Agilent 6490 Triple Quadrupole MS/MS system. UPLC-MS/MS parameters, such as precursor ions and product ions for the target ABs and their ILISs, were adjusted and optimized with collision voltage (CE) and cell accelerator voltage (CAV) for the UPLC-MS/MS instrument employed in this study (Agilent 1290 Infinity LC+Agilent 6490 Triple Quadrupole MS/MS, USA). Detailed information about the optimized ESI-MS/MS parameters for the detection of the target ABs as well as their ILISs by the 
multiple reaction monitoring (MRM) mode are shown in Table A.3 (Supplementary Information). In addition, detailed information about the instrumental detection limits (IDLs), instrumental quantification limits (IQLs), and SPE recoveries of target antibiotics are summarized in Tables A4-A5 (Supplementary Information). Method detection limit (MDL) and method quantification limit (MQL) for target antibiotics in urban canal and lake samples are summarized in Table 1.

\subsection{Environmental risk assessment}

As aforementioned, the occurrence of antibiotics in the environment may result in genetic or mutational changes in sensitive bacteria, which allows bacteria to survive and further multiply as ARB that carry ARGs (Martinez, 2009; Knapp et al., 2010; Graham et al., 2016). Antibiotic residues in the environment may create selection pressure on the environmental microbiome and generate environmental reservoirs of ARB and ARGs (Forsberg et al., 2012; Blair et al., 2015; Ben et al., 2019). In addition, the occurrence of antibiotics in the water environment has been well documented to be potentially toxic to sensitive aquatic organisms such as algae, crustaceans or fish (Isidori et al., 2005; Ando et al., 2007; Richardson and Ternes, 2011; Havelkova et al., 2016; Minguez et al., 2016). Therefore, an environmental risk assessment of antibiotics in urban canals and lakes should be considered in light of the two following aspects: (i) antimicrobial resistance (AMR) development and (ii) ecological toxicity to aquatic organisms. It was noted that the potential risks of antibiotics in urban canals and lakes were indirectly assessed based on their MEC and PNEC values collected from the literature.

\subsubsection{Possible risk of antibiotics for resistance selection}

The possible risk of antibiotics for antimicrobial resistance selection $\left(\mathrm{RQ}_{\mathrm{AMR}}\right)$ was indirectly evaluated based on the maximal $\mathrm{MEC}$ in water sample and lowest $\mathrm{PNEC}_{\mathrm{AMR}}$ for each single compound as depicted in Eq. (1).

$R Q_{A M R}=\frac{M E C_{M a x}}{P N E C_{A M R}}$ 
The risk was categorized into two levels: (i) low risk with $\mathrm{RQ}_{\mathrm{AMR}} \leq 1.0$ and (iii) possible risk with the $\mathrm{RQ}_{\mathrm{AMR}}>1.0$. In this study, the lowest $\mathrm{PNEC}_{\mathrm{AMR}}$ value collected from the literature (Kümmerer and Henninger, 2003; Bengtsson-Palme and Larsson, 2016) was used to calculate $\mathrm{RQ}_{\mathrm{AMR}}$.

\subsubsection{Ecological risk of antibiotics to aquatic organisms}

The environmental risk of antibiotics to aquatic organisms (i.e. algae, crustaceans, or fish) was calculated as the ratio between the measured environmental concentrations in water (MEC) at

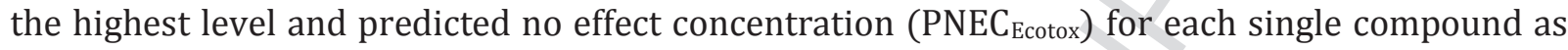
depicted in Eq. (2).

$R Q_{E \operatorname{cotox}}=\frac{M E C_{\text {Max }}}{P N E C_{E \operatorname{cotox}}}$

where $\mathrm{RQ}_{\mathrm{Ecotox}}$ is the risk quotient, $\mathrm{RQ}_{\mathrm{Ecotox}}>1.0$ indicating a risk to aquatic organisms, while the ecological risk is minor when $\mathrm{RQ}_{\mathrm{Ecotox}}<1.0$.

In this study, $\mathrm{PNEC}_{\mathrm{Ecotox}}$ values were estimated based on one of the following concentrations: no observed effect concentration (NOEC), lowest observed effect concentration (LOEC), half maximal inhibitory concentration ( $\left.\mathrm{IC}_{50}\right)$, half maximal lethal concentration $\left(\mathrm{LC}_{50}\right)$, or halfmaximal effective concentration $\left(\mathrm{EC}_{50}\right)$ values from a set data of short-term or long-term toxicity tests and an appropriate assessment factor (AF) as represented in Eq. (3).

$P N E C_{\text {Ecotox }}=\frac{\operatorname{Min}\left\{N O E C, L O E C, E C_{50}, L C_{50}, I C_{50}\right\}}{A F}$

where AF varies from 10 to 1000 , depending on the nature of toxicological data. For example, AF of 1000 is often used to calculate $\mathrm{PNEC}_{\mathrm{Ecotox}}$ using short-term ecotoxicological data $\left(\mathrm{LC}_{50}, \mathrm{IC}_{50}\right.$, or $\mathrm{EC}_{50}$ ), while lower $\mathrm{AF}$ values (e.g., 10-100) are frequently used to determine $\mathrm{PNEC}_{\mathrm{Ecotox}}$ based on long-term ecotoxicological data (LOEC or NOEC) with a relevant tested organisms (EC, 2003). It is noteworthy that toxicological data for each compound is largely dependent on target species, exposure time and endpoint test. For example, NOEC of AMP for Anabaena cylindrical NIES-19 was $13 \times 10^{3} \mathrm{ng} / \mathrm{L}$, while its value for Microcystis aeruginosa NIES-44 was $31 \mathrm{ng} / \mathrm{L}$ (Ando et al., 
2007). Similarly, there is significant difference in the $\mathrm{EC}_{50}$ value of AMX between Microcystis aeruginosa $\left(3.7 \times 10^{3} \mathrm{ng} / \mathrm{L}\right)$ and Pseudokirchneriella subcapitata $\left(1.5 \times 10^{9}\right)$ (Lützhøft et al., 1999; Gonzalez-Pleiter et al., 2013). In this study, toxicological data were collected from the published literature and database as summarized in Table A6 (Supplemetary Information). $\mathrm{PNEC}_{\mathrm{Ecotox}}$ of antibiotics is calculated based on the lowest value of toxicological data from the existing literature and summarized in Table 4.

\section{Results and discussion}

\subsection{Occurrence of antibiotics in urban canals}

Table 2 shows the concentration and detection frequency (DF) of antibiotics in urban canals impacted by raw wastewater sources. All target antibiotics, except CFEX, CFZ, CTC, MER and MIN, were detected in urban canal water samples with the DF ranging from 25 to $100 \%$, depending on the compound. For instance, AZT, CLAR, CLI, ENFLX, ERY-H $\mathrm{O}_{2}$, LIN, OFLX, SMX, and TMP were ubiquitous ( $\mathrm{DF}=100 \%)$ in urban canal water samples. The concentrations of detected antibiotics significantly varied from below method quantification limit (MQL) to several tens of micrograms per liter. Sulfonamides (SMX and SMZ), fluoroquinolones (CIPX, ENFLX, and OFLX), macrolides (AZT, CLAR, ERY, ERY- $\mathrm{H}_{2} \mathrm{O}$, and TYL), lincosamides (LIN and CLI) and trimethoprim were frequently found in urban canal water samples. In contrast, beta-lactams (AMP, CFEX, CFZ, and MER), tetracyclines (CTC, MIN, and OXY) were rarely detected in urban canals. Monitoring results also showed that there was a variation in the concentration between sampling points at each urban canal (Fig. A2-A3, Supplementary Information). However, no statistically significant difference (unpaired T-test, $p>0.05$ ) in the concentrations of most antibiotics was observed between TL and KN canals (Fig. 2).

\subsubsection{Occurrence of beta-lactams}

Among the five investigated beta-lactam antibiotics, only AMX and AMP were detected in urban canals with the DF $>67.9 \%$ (Table 2) Although beta-lactams belonging to the second and thirdgeneration cephalosporins were reported to be the most commonly sold antibiotics in Vietnam 
(Nguyen et al., 2013; Nga et al., 2014), CFEX and CFZ were not found in any sewage samples collected from urban canals in this study. The absence of the third-generation beta-lactam (CFZ and CFEX) and carbapenem (MER) might be due to the lower consumption of these drugs compared to other antibiotics. Another possible reason for the absence of CFEX, CFZ and MER in urban canals might be due to their rapid degradation in the human body via the renal route (Kemmerich et al., 1983) and high environmental attenuation rates (i.e. biodegradation, sorption, and other abiotic degradations) in urban canals. Previous studies reported that degradation of beta-lactam antibiotics could take place under acidic/alkaline conditions or by reactions with weak nucleophiles such as water or metal ions in wastewater samples (Le-Minh et al., 2010; Hirte et al., 2016). In a previous study, Hirte et al. (2016) found that the hydrolytic half-life of AMX in water was largely dependent upon environmental conditions. For example, half-lives of AMX were 128.2 and $208.3 \mathrm{~h}$ under acidic $(\mathrm{pH}=3)$ and neutral $(\mathrm{pH}=7)$ conditions, while it was only $9.7 \mathrm{~h}$ under alkaline conditions $(\mathrm{pH}=11)$. Alternatively, beta-lactam antibiotics in urban canals can be degraded under sunlight (Timm et al., 2019). In a recent study, Timm et al. (2019) found that half-lives of beta-lactam antibiotics under simulated environmental conditions $\left(1 \mathrm{~kW} / \mathrm{m}^{2}\right)$ varied from 3.2 to $7 \mathrm{~h}$. In addition, beta-lactam antibiotics might be enzymatically hydrolysed by beta-lactamases (Rodríguez et al., 2018), which are widespread enzymes and produced by many species to inactivate the pharmacological effects of the beta-lactam antibiotics. These are reasons why beta-lactam antibiotics are generally detected at relatively low concentrations in urban canals or not detected at all, although this kind of antibiotics are among the most widely used prescribed antibiotics (Cha et al., 2006; Watkinson et al., 2007; Nguyen et al., 2013). In comparison to other countries, the concentrations of beta-lactam AMX in urban canal water samples (i.e. municipal wastewater) of this study are comparable to those reported in China, India, Japan, and Singapore (Minh et al., 2009; Matsuo et al., 2011; Tran et al., 2016b).

\subsubsection{Occurrence of macrolides}

Macrolide antibiotics (AZT, CLAR, ERY, ERY- $\mathrm{H}_{2} \mathrm{O}$, and TYL) were the most frequently detected compounds in urban canals with the DF ranging from 67.9 to $100 \%$ (Table 2). AZT, CLAR and 
ERY- $\mathrm{H}_{2} \mathrm{O}$ were omnipresent in urban canal water samples (DF $=100 \%$ ), while ERY and TYL was at a lower DF (67.9-75\%). The lower DF of ERY in urban canals could related to its rapid transformation to ERY- $\mathrm{H}_{2} \mathrm{O}$ under acidic conditions $(\mathrm{pH}<7.0)$ (Díaz-Cruz and Barceló, 2005; Zhou et al., 2012; Tran et al., 2016b; Tran et al., 2018). In fact, the detection of ERY- $\mathrm{H}_{2} \mathrm{O}$ in urban canals in this study indicated that there was a transformation of ERY in the environmental samples.

The concentrations of macrolides significantly fluctuated from $<M Q L$ to a few tens of micrograms per liter. Among the investigated macrolides, ERY was found at the highest median concentration (5,542 ng/L), followed by CLAR (700 ng/L), ERY-H 20 (581 ng/L), AZT (524 ng/L), and TYL (28 ng/L). The distribution patterns of macrolide antibiotics in urban canals impacted by raw municipal wastewater sources of this study are quite different from those in raw wastewater in other countries (Miao et al., 2004; Gobel et al., 2007; Tran et al., 2016b). For example, in Singapore, CLAR and AZT were more frequently detected in raw wastewater at higher concentrations compared to ERY/ERY- $\mathrm{H}_{2} \mathrm{O}$ (Tran et al., 2016b). However, this study found that the median concentration of ERY appeared to be higher than that of AZT and CLAR by one order of magnitude, probably due to its usage pattern. In fact, ERY was reported to be one of the most commonly sold antibiotics in Vietnam (Nguyen et al., 2013; Nga et al., 2014). Moreover, Nga et al., (2014) also reported that the price of ERY (i.e. 0.08 USD for Pack/250 mg) was significantly lower than that of AZT (5.19 USD for Bottle/200 mg/5 ml) or CLAR (0.43 USD for Tablet/250 mg) by a factor of 5-60. For this reason, the usage patterns of macrolides in Vietnam can be different from developed countries (i.e. Singapore, Canada or Switzerland). In addition, the differences in the distribution characteristics and concentrations in urban canals of an antibiotic could be due to the difference in land use patterns, population, weather conditions, and sewer systems (combined or separate sewer systems).

\subsubsection{Occurrence of sulfonamides and reductase inhibitor}

Sulfonamides (SMX and SMZ) and the reductase inhibitor (TMP) were ubiquitously detected in urban canals with DF $>92.9 \%$ (Table 2), especially the two compounds, SMX and TMP, which were omnipresent in urban canal water samples $(\mathrm{DF}=100 \%)$. The concentrations of sulfonamide 
antibiotics (SMX and SMZ) significantly ranged from <MQL to $15,591 \mathrm{ng} / \mathrm{L}$. In general, the concentrations of SMX in urban canals impacted by raw wastewater sources in Hanoi were substantially higher than those in raw wastewater in North America, Europe, and other Asian countries (Tran et al., 2018). The coexistence of SMX and TMP in urban canals could be interpreted by the simultaneous consumption of these two drugs in effective treatment against a wide variety of potential bacterial infections. In fact, SMX and TMP are often administered in combination at a ratio of 1:5 (Gobel et al., 2005). However, the median concentration of TMP in this study was significantly lower than that of SMX by one order of magnitude.

\subsubsection{Occurrence of fluoroquinolones}

Fluoroquinolone antibiotics (e.g., CIPX, ENFLX, and OFLX) are commonly used to treat a large number of human infection diseases caused by several types of Gram-negative and Gram-positive bacteria. In this study, fluoroquinolone antibiotics were the most frequently detected antibiotic classes in the urban canals. The detection frequency of these compounds ranged from 85 to $100 \%$ (Table 2), depending on the compound. The concentrations of fluoroquinolone antibiotics largely varied from $<M Q L$ to several thousands of ng/L (Table 2). For example, the highest concentration of CIPX in urban canal water was 3,035 ng/L. Generally, the concentrations of CIPX in urban canals impacted by raw municipal wastewater sources of this study tend to be lower than those in raw wastewater in other countries. For example, Tran et al. (2016b) found that the median concentration $(3,496 \mathrm{ng} / \mathrm{L})$ of CIPX in raw municipal wastewater in Singapore was significantly higher than that in this study (302 ng/L, Table 2) by one order of magnitude. The presence of CIPX in urban canals could be a result of the direct discharge of hospital effluents as well as household effluents from residential areas (Duong et al., 2008). In general, the concentrations of CIPX in urban canals of this study are much lower than those in hospital effluents $(1,100-10,900$ ng/L) as reported by Duong et al. (2008). Similarly, the median concentration of OFLX in urban canals of this study (272 ng/L) appeared to be significantly lower than that in hospital effluent (7,500 ng/L) as reported by Thai et al. (2018). It is noteworthy that ENFLX (a veterinary antibiotic) was also detected $100 \%$ in the collected urban canal samples. This finding seems to be 
in contrast to an earlier study by (Rodriguez-Mozaz et al., 2015), in which ENFLX was reported to be absent in Spain's domestic wastewater samples. However, the detection of ENFLX in urban canal water samples (i.e. urban sewage) in this study is in agreement with that reported in USA (Karthikeyan and Meyer, 2006) and Tunisia (Harrabi et al., 2018). The occurrence of ENFLX in urban canals could be attributed to the presence of certain veterinary practices, as ENFLX is widely used to treat bacterial infections in animals (e.g. cats and dogs) caused by Gram-positive and Gram-negative bacteria, such as Pseudomonas aeruginosa, Klebsiella, E.coli., Enterobacter, Campylobacter, Shigella, Salmonella, Aeromonas, Haemophilus, Proteus, Yersinia, Serratia, Vibrio, Brucella, Chlamydia, Staphylococci, Mycoplasma, and Mycobacterium. In fact, feces from dogs and cats of households in Hanoi tend to be directly discharged into the environment (urban canals).

\subsubsection{Occurrence of lincosamides}

To date, lincosamines (CLI and LIN) have been less reported in domestic wastewater from North American and European countries (Watkinson et al., 2007; Tran et al., 2018) as they are mainly used to treat animal infections. However, CLI and LIN were ubiquitously detected (DF $=100 \%)$ in urban canal water samples in Hanoi. The omnipresence of CLI and LIN in urban canals is in agreement with their usage. In fact, Nga et al. (2014) reported that CLI and LIN were 2 out of 20 most commonly sold antibiotics in Vietnam.

The concentrations of lincosamide antibiotics largely fluctuated from ng/L to $\mu \mathrm{g} / \mathrm{L}$ (Table 2). For example, concentrations of LIN ranged from 67 to 1,968 ng/L. The concentrations of LIN in urban canal water samples tend to be higher than those of CLI by 1-2 orders of magnitude. This distribution pattern is consistent with that reported in earlier studies (Behera et al., 2011; Gurke et al., 2015; Subedi et al., 2015; Tran et al., 2016b; Yang et al., 2017; Tran et al., 2018). Until now, there is no report on the occurrence of lincosamides in the aquatic environment in Vietnam. As such, this study provides the first information on the occurrence of this antibiotic class in urban canals impacted by raw municipal wastewater sources.

\subsubsection{Occurrence of tetracyclines}


Among the investigated tetracyclines (CTC, MIN, OXY and TET), only OXY and TET were detected in urban canal water samples with a DF of 25 and 92.5\%, respectively (Table 2). The concentrations of OXY and TET also varied significantly from <MQL to $635 \mathrm{ng} / \mathrm{L}$. The concentrations of OXY and TET in urban canals of this study are significantly lower than those found in raw wastewater in North America and other Asian countries, e.g., China and Singapore (Miao et al., 2004; Karthikeyan and Meyer, 2006; Gulkowska et al., 2008; Sun et al., 2016; Tran et al., 2016b; Tran et al., 2018). In comparison to other antibiotic classes (e.g. beta-lactams, macrolides, and fluoroquinolones), tetracyclines are not the most commonly sold antibiotics in Vietnam (Nguyen et al., 2013; Nga et al., 2014). As a result, the concentrations of tetracyclines in urban canal water samples were significantly lower than those observed for other classes of antibiotics. In a previous study, it was reported that tetracyclines (OXY and TET) were detected in different sources of water (e.g. aquaculture, animal husbandry, hospital and household) at concentrations $<1,000 \mathrm{ng} / \mathrm{L}$ (Shimizu et al., 2013). In addition, the low concentration of tetracyclines in urban canals could be due to their abiotic transformation (photo-degradation by direct sunlight irradiation (Chen et al., 2008; Zaranyika et al., 2015), sorption onto sediment/suspended solids (Zaranyika et al., 2015), possible complexation with divalent metal cations such as $\mathrm{Cu}^{2+}, \mathrm{Mg}^{2+}$ or $\mathrm{Ca}^{2+}($ Carlotti et al., 2012) and biodegradation (Huang et al., 2012; Zaranyika et al., 2015). In an earlier study, Chen et al (2008) found that direct photolysis is the main process of photodegradation of tetracycline under sunlight irradiation. In addition, the presence of nitrate, bicarbonate, ferric ions and humic acids also contributed to the indirect photolysis of tetracycline.

\subsubsection{Occurrence of other antibiotic classes}

The glycopeptide antibiotic, VAN, was often detected in urban canal water samples with a DF of 71.4\%. The concentrations of this compound ranged widely from <MQL to $249 \mathrm{ng} / \mathrm{L}$. The low concentrations of VAN could be explained by the lower consumption of this antibiotic in households. In fact, VAN is still considered as gold standard to treat methicillin-resistant Staphylococcus aureus (Holmes et al., 2015). In Vietnam, VAN is strictly reserved for the hospital 
sector and rarely sold/bought in the over-the-counter market. In comparison to other countries, the concentrations of VAN in urban canals impacted by raw municipal wastewater sources in this study are significantly lower than those in raw wastewater as reported in European countries (Dinh et al., 2017) and Singapore (Tran et al., 2016b).

It is noteworthy that chloramphenicol (CAP) was also often detected $(\mathrm{DF}=96.4 \%)$ in urban canal water samples, but its concentrations appeared to be significantly lower than other antibiotic classes (i.e. beta-lactams, macrolides, sulfonamides, and fluoroquinolones). The concentrations of CAP in urban canals fluctuated considerably from $<$ MQL to $155 \mathrm{ng} / \mathrm{L}$. The low concentrations of CAP can be attributed to the lower consumption of this banned antibiotic in many countries (Kasprzyk-Hordern et al., 2009; Tong et al., 2009; Tran et al., 2016b).

In comparison with other countries, the concentrations of CAP in urban canals of this study are comparable with those in raw wastewater in Europe (Kasprzyk-Hordern et al., 2009; Gracia-Lor et al., 2012) and Singapore (Tran et al., 2016b). In China, however, CAP was more often detected in wastewater with concentrations up to $2,430 \mathrm{ng} / \mathrm{L}$ in raw wastewater and 1,050 ng/L in treated wastewater (Peng et al., 2006; Minh et al., 2009; Sui et al., 2011). The high concentrations of CAP in China could be interpreted by the high consumption and easy accessibility of this antibiotic in over-the-counter markets.

\subsection{Occurrence of antibiotics in urban lakes}

Table 3 summarises the concentration and detection frequency of the investigated antibiotics in urban lakes in Hanoi, Vietnam. 16 out of 23 antibiotics were detected in urban lakes with the DF ranging from 8 to 100\%, depending on the compound and sampling site. For example, macrolides (AZT, CLAR, and ERY- $\mathrm{H}_{2} \mathrm{O}$ ), fluoroquinolones (ENFLX and OFLX), lincosamides (CLI and LIN), sulfonamide (SMX) and TMP were omnipresent in urban lakes (DF=100\%), while beta-lactams (AMP, AMX, CFEX, CFZ, and MER) were rarely detected. The concentrations of antibiotics fluctuated largely from $<$ MQL to several thousand ng/L, depending on the compound and sampling location. The variation in the concentrations of detected antibiotics in urban lakes is 
larger than in urban canals due to dilution. As shown in Fig. 3, most of the antibiotics were found in the WL and YS lakes at higher concentrations compared to those in HK lake. Of the 3 urban lakes, WL has the highest concentration of antibiotics followed by YS lake since YS lake receives treated effluent rather than raw wastewater. In addition, it was noted that there was a variation in the concentrations of antibiotics at different sampling points in two urban lakes (WL and YS). For example, the concentrations of most antibiotics at the sampling WL1 in West Lake tended to be higher than those at other sites in this urban lake (Fig. A4, Supplementary Information). Among the investigated lakes, HK has the lowest concentration of antibiotics and least variation (Fig. A6, Supplementary Information) because it only take stormwater runoff and is a small lake.

In comparison to urban canals, the concentrations of the vast majority of target antibiotics in urban lakes were significantly lower (unpaired T-test, $\mathrm{p}<0.05$ ) than those in urban canals possibly due to dilution (Fig. A.1, Supplementary Information). The presence of antibiotics in these urban lakes could be attributed to at least one of the following pollution sources: (i) sewer leakage (Phillips and Chalmers, 2009; Tran et al., 2019), (ii) illicit discharge of raw sewage (Phillips and Chalmers, 2009), (iii) combined sewer overflows (Phillips and Chalmers, 2009; Tran et al., 2019), and (iv) urban stormwater runoff (Phillips and Chalmers, 2009). The occurrence of each class of antibiotics is discussed in more detail in the following sections.

\subsubsection{Beta-lactam antibiotics in urban lakes}

Similar to occurrence patterns in urban canals, the investigated beta-lactam antibiotics (AMP, AMX, CFZ, CFEX and MER) were rarely detected in urban lakes. Only AMX was detected in several water samples collected from WL and YS lakes (Table A.8, Supplementary Information). As aforementioned, WL and YS lakes are impacted by both point- and non-point pollution sources (i.e. discharge of untreated/treated sewage, combined sewer overflows, sewer leakage, and urban runoff). In particular, YS Lake is receiving treated wastewater from a local municipal sewage treatment plant (STP). The detection of AMX in surface water samples in this study is consistent with that in other countries such as France (Dinh et al., 2011), Italy (Riva et al., 2019), and UK (Kasprzyk-Hordern et al., 2008). 
However, AMP was not detected in any urban lake water samples of this study. This result seems to be different from observations in other countries, e.g., USA, Ghana, and South Africa (Cha et al., 2006; Agunbiade and Moodley, 2016; Azanu et al., 2018). For example, Agunbiade and Moodley (2016) and Azumu et al (2018) reported that AMP was found in $100 \%$ of surface water samples in Africa with concentrations up to $5,509 \mathrm{ng} / \mathrm{L}$. For other investigated beta-lactams (CFEX, CFZ and MER), their absence in urban lakes is consistent with the pattern observed in the urban canals.

In short, the rare occurrence of beta-lactams in the urban lakes could be interpreted by their rapid attenuation rates (i.e. biodegradation, sorption and abiotic degradation) in the aquatic environment (Gozlan et al., 2010; Hirte et al., 2016; Tran et al., 2018; Timm et al., 2019).

\subsubsection{Macrolide antibiotics in urban lakes}

All the investigated macrolide antibiotics (AZT, CLAR, ERY, ERY- $\mathrm{H}_{2} \mathrm{O}$, and TYL) were detected in urban lakes. The DF of these compounds varied from 24 to $100 \%$ (Table 3), depending upon the compound and sampling site. For example, AZT, CLAR and ERY- $\mathrm{H}_{2} \mathrm{O}$ were omnipresent in all the studied urban lakes $(\mathrm{DF}=100 \%)$, while TYL was rarely in WL and HK lakes with a $\mathrm{DF} \leq 8.3 \%$ (Table A.8, Supplementary Information). In general, the occurrence pattern of macrolides in lake water of this study is in agreement with that of surface water from Singapore (Tran et al., 2016a), Spain (Rodriguez-Mozaz et al., 2015), China (Zhou et al., 2016) and Pakistan (Khan et al., 2013), in which macrolides were more frequently detected in surface waters with a DF $>90 \%$ (Table 3).

The concentrations of macrolides in urban lakes also ranged substantially from $<$ MQL to a few hundreds of ng/L. ERY was the most abundant macrolides detected in urban lakes with its concentration up to $741 \mathrm{ng} / \mathrm{L}$. It was noted that the concentrations of ERY and CLAR in two urban lakes (WL and YS) were sometimes close to or exceeding $\mathrm{PNEC}_{\mathrm{AMR}}$ value for antibiotic resistance selection (Table 4) as reported by Kümmerer and Henninger (2003) and PNEC Ecotox for ecological toxicity to aquatic ecosystems (Table 5). In contrast, AZT and TYL were consistently detected at concentrations lower than their $\mathrm{PNEC}_{\mathrm{AMR}}$ for antibiotic resistance selection (Table 4). However, it 
is noted that $\mathrm{PNEC}_{\mathrm{ARM}}$ and $\mathrm{PNEC}_{\mathrm{Ecotox}}$ values are largely dependent on target species and assessment factor (i.e. AF 1-1000).

In addition to the occurrence in dissolved phase, macrolide antibiotics (i.e. AZT, CLAR, and ERY) were reported to be present in sediments/suspended solids in urban lakes (Zhao et al., 2016; Kafaei et al., 2018) since these compounds have $\log K_{\text {ow }}>3.0$ (Table A1, Supplementary Information) and exist mainly as cations under environmental pH 6-8 (Tran et al., 2016b). Indeed, Zhao et al. (2016) found that ERY was detected in river sediment at concentrations up to $13.89 \mathrm{ng} / \mathrm{g}$. In a recent study, Kafaei et al (2018) also observed the presence of two macrolide antibiotics (AZT and ERY) intertidal sediment. Therefore, the occurrence of CLAR and ERY in urban lakes might have the possible risks for resistance selection and aquatic ecosystems.

\subsubsection{Sulfonamides and trimethoprim in urban lakes}

Sulfonamides (SMX and SMZ) and trimethoprim (TMP) were ubiquitously detected in urban lakes with a DF $>96 \%$, in which SMX and TMP were omnipresent in lake water samples (DF=100\%). The concentrations of sulfonamides significantly ranged from $<M Q L$ to a few thousands of ng/L. SMX was found to be the most abundant compound detected in urban lake water samples with a median concentration of $255 \mathrm{ng} / \mathrm{L}$. The concentrations of SMX in lake waters of this study are higher than those in the surface water of Singapore (Tran et al., 2016a), Spain (Rodriguez-Mozaz et al., 2015), Germany (Hirsch et al., 1999) and China (Zhang et al., 2014), but comparable with

other regions such as France and Pakistan (Dinh et al., 2011; Khan et al., 2013). The high concentration of SMX in urban lakes (YS and WL) could be attributed to the direct discharge of untreated/treated wastewater and urban runoff into the urban lakes. For SMZ and TMP, their concentrations in urban lakes in this study seem to be comparable with those observed in China, Singapore, and Spain (Zhang et al., 2014; Rodriguez-Mozaz et al., 2015; Tran et al., 2016a), but significantly lower than other regions such as Africa and Asia-Pacific, as reported by aus der Beek et al. (2016). Despite the ubiquitous detection ( $\mathrm{DF} \geq 96 \%$, Table 3), the concentrations of SMX, SMZ and TMP in all urban lakes were lower than their $\mathrm{PNEC}_{\mathrm{AMR}}$ for antibiotic resistance selection 
(Table 4), but sometimes exceeded their $\mathrm{PNEC}_{\mathrm{Ecotox}}$ for ecological toxicity to aquatic organisms (Table 5).

\subsubsection{Fluoroquinolones in urban lakes}

Fluoroquinolones (CIPX, ENFLX and OFLX) were often found in the urban lakes with a DF ranging from 60 to 100\%, in which ENFLX and OFLX were omnipresent in the urban lakes (DF=100\%). The concentrations of fluoroquinolone antibiotics in urban surface waters substantially varied from $<\mathrm{MQL}$ to several hundreds of ng/L, depending on the compound and sampling site. For example, CIPX, ENFLX and OFLX were consistently detected at WL and YS lakes at significantly higher levels (unpaired T-test, $\mathrm{p}<0.05$ ) compared to those in HK lake (Fig. 3). The concentrations of the three fluoroquinolone antibiotics in two of three urban lakes (WL and YS) were sometimes greater than their $\mathrm{PNEC}_{\mathrm{AMR}}$ for antibiotic resistance selection (Kümmerer and Henninger, 2003; Bengtsson-Palme and Larsson, 2016), but lower than their $\mathrm{PNEC}_{\mathrm{Ecotox}}$ for ecological toxicity to aquatic organisms (Tables 4-5).

\subsubsection{Lincosamides in urban lakes}

In this study, lincosamides (CLI and LIN) were detected at 100\% frequency in urban lake water samples, but their concentrations tended to be less than $100 \mathrm{ng} / \mathrm{L}$ (Table 2). The occurrence pattern of CLI and LIN in the urban lakes is similar to that in the urban canals. For example, the concentrations of LIN were consistently higher than those of CLI. Like other antibiotics, the occurrence pattern of lincosamides in urban lakes in this study is similar to that observed in surface water from China, Pakistan and Singapore (Khan et al., 2013; Tran et al., 2016a; Chen et al., 2018). The concentrations of lincosamides in the urban lakes of this study were substantially lower than their $\mathrm{PNEC}_{\mathrm{AMR}}$ for resistance selection as well as $\mathrm{PNEC}_{\mathrm{Ecotox}}$ for ecological toxicity to aquatic organisms (Tables 4-5).

\subsubsection{Tetracyclines in urban lakes}

Among the investigated tetracyclines, only TET was detected in WL lake with a low DF (16.7\%), as represented in Table A.8 (Supplementary Information). The absence of other tetracyclines (i.e. 
CTC, MIN, and OXY) in urban lakes is consistent with their occurrence patterns in urban canals as discussed in section 3.1.6. This absence of tetracyclines in urban lakes might be interpreted by lower consumption of tetracyclines compared to other antibiotic classes (Nguyen et al., 2013). Generally, the concentrations of TET in urban lakes of this study are comparable with those in surface water in some countries, e.g., China, France and Pakistan (Dinh et al., 2011; Khan et al., 2013; Chen et al., 2018). Results showed that the concentrations of TET in urban lakes were substantially lower than its $\mathrm{PNEC}_{\mathrm{AMR}}$ for antibiotic resistance selection as well as $\mathrm{PNEC}_{\mathrm{Ecotox}}$ for ecological toxicity to aquatic organisms (Tables 4-5).

\subsubsection{Glycopeptide and amphenicol antibiotics in urban lakes}

Chloramphenicol (CAP) was detected relatively frequently in urban lakes with a DF of $68 \%$, however, its median concentration was $<10 \mathrm{ng} / \mathrm{L}$. In general, the concentrations of CAP in urban lakes in this study are comparable with those in surface waters of Germany, Korea and Singapore (Hirsch et al., 1999; Choi et al., 2008; Tran et al., 2016a).

The glycopeptide VCM was also often detected in WL and YS lakes (Table A.8, Supplementary Information), but its concentrations were relatively low ( $\leq 26 \mathrm{ng} / \mathrm{L})$. In general, the concentrations of CAP and VCM in urban lakes were significantly lower than their PNEC $_{\text {ARM }}$ for antibiotic resistance selection as well as $\mathrm{PNEC}_{\mathrm{Ecotox}}$ for ecological toxicity to aquatic organisms (Tables 3-4).

\subsection{Environmental risk assessment for antibiotics}

\subsubsection{Environmental risk of antimicrobial resistance development}

The environment risk of antibiotics for antimicrobial resistance selection in urban canals and urban lakes is shown in Table 6, in which $\mathrm{RQ}_{\mathrm{AmR}}$ value was calculated based on the maximal measured environmental concentrations $\left(\mathrm{MEC}_{\max }\right)$ and lowest $\mathrm{PNEC}_{\mathrm{AMR}}$ for antibiotic resistance selection (Table 4). As summarised in Table 6, most of the antibiotics detected in urban canals, such as beta-lactams (AMP and AMX), macrolides (AZT, CLAR, and ERY), fluoroquinolones (CIPX, ENFLX and OFLX) and trimethoprim (TMP) sometimes were found at concentrations higher than 
their $\mathrm{PNEC}_{\mathrm{ARM}}$ (i.e. $\mathrm{RQ}_{\mathrm{AMR}}>1.0$ ), indicating that the occurrence of these antibiotics in urban canals perhaps lead to a possible risk for antibiotic resistance evolution. Indeed, Phan et al. (2011) found the ubiquitous occurrence of SMX- and ERY-resistant bacteria in urban canals in Hanoi at significantly high levels up to $2.5 \times 10^{6} \mathrm{CFU} / \mathrm{mL}$ for SMX-resistant bacteria and $2.5 \times 10^{5} \mathrm{CFU} / \mathrm{mL}$ for ERY-resistant bacteria. The percentage of the isolates from urban canal water samples resistant to SMX and ERY were relatively high, up to $99.44 \%$ for SMX-resistant bacteria and 38.8\% for ERY-resistant bacteria. In addition, Phan et al (2011) was observed that there was a positive correlation between the concentrations of antibiotics and their resistant bacteria under the dry weather conditions. Other detected antibiotics, such as LIN, TET, SMX VCM, CAP and CLI, showed a low risk $\left(\mathrm{RQ}_{\mathrm{AmR}}<1\right)$ for antibiotic resistance development in urban canals as their concentrations were observed to be considerably lower than PNEC $_{\text {ARM. }}$.

In short, the occurrence of antibiotic residues in urban canals might pose a possible risk to public health because water from the urban canals is mainly used for irrigation activities in suburban areas. Consequently, antibiotic residues may accumulate in crops (i.e. vegetables and grains) through uptake from urban sewage-irrigated croplands (Li et al., 2014; Pan et al., 2014). For example, Li et al. (2014) reported that three quinolone antibiotics (i.e. ciprofloxacin, enrofloxacin, and norfloxacin) were found in vegetables in Shandong Province, China at concentrations up to $658.3 \mu \mathrm{g} / \mathrm{kg}$ for norfloxacin, $32.3 \mu \mathrm{g} / \mathrm{kg}$ for enrofloxacin, and $27.5 \mu \mathrm{g} / \mathrm{kg}$ for ciprofloxacin. In another study, Pan et al. (2014) also observed the presence of four selected antibiotics (i.e. tetracycline, sulfamethazine, norfloxacin, and chloramphenicol) in Chinese radish. In particular, Pan et al. (2014) also reported that chloramphenicol and norfloxacin exhibited higher concentrations in vegetables than those of tetracycline and sulfamethazine.

Regarding the possible risk of antibiotics for resistance selection in urban lakes, Table 6 shows that beta-lactam AMX, macrolides (CLAR and ERY), and fluoroquinolones (ENFLX and OFLX) were found in WL and YS lakes at concentrations sometimes higher than their PNEC $_{\text {ARM }}$ (i.e. $\mathrm{RQ}_{\mathrm{ARM}}>1$ ), indicating that the presence of these antibiotics in urban lakes might lead to a possible risk for antibiotic resistance evolution in the nonclinical environment. For other detected 
antibiotics, low risk $\left(\mathrm{RQ}_{\mathrm{AmR}} \leq 1\right)$ was posed for resistance selection. However, there has been no report on the occurrence of ARB and ARGs in urban lakes in Hanoi, especially for WL where recreational activities (i.e. boating, rowing, kayaking, fishing and swimming in surface water) often take place. Therefore, further studies on the occurrence of ARB and ARGs in urban lakes are recommended.

\subsubsection{Environmental risk of antibiotics to aquatic ecosystems}

The environmental risk of antibiotics to aquatic ecosystems in urban lakes and canals was assessed based on their maximal MEC and $\mathrm{PNEC}_{\mathrm{Ecotox}}$. The $\mathrm{PNEC}_{\mathrm{Ecotox}}$ used in this study was estimated based on the ecotoxicological data (NOEC, $\mathrm{LOEC}$, and $\mathrm{EC}_{50}$ ) collected from the literature (Table A6, Supplementary Information) and a suitable assessment factor, as summarized in Table 5.

The environmental risk assessment for the detected antibiotics in the investigated urban lakes and urban canals is shown in Table 7. Among the detected antibiotics in urban lakes, beta-lactam AMX, macrolides (CLAR, ERY, and TYL), lincosamides (CLI and LIN), fluoroquinolones (CIPX, ENFLX, and OFLX), sulfonamides (SMX and SMZ), tetracycline (TET), and trimethoprim (TMP) exhibited their $\mathrm{RQ}_{\mathrm{Ecotox}}>1.0$, implying that the presence of these antibiotics in the investigated urban lakes perhaps lead to a possible ecological risk to aquatic organisms (i.e. algae).

For urban canals, several detected antibiotics (such as AMP, AMX, CLAR, ERY, and SMX) were sometimes found at concentrations higher than their $\mathrm{EC}_{50}$ or NOEC, implying that these antibiotics might pose a possible ecological risk to the aquatic ecosystems and should be given priority controls.

\section{Conclusions}

This study provides comprehensive analysis of the occurrence of 23 target antibiotics in urban canals and urban lakes in Hanoi. Of these, 18 target antibiotics were detected in urban canal water samples with a DF ranging from 25 to $100 \%$. SMX, ERY, and AMX were the most abundant antibiotics detected in urban canals with median concentrations $>1000 \mathrm{ng} / \mathrm{L}$, while other 
antibiotics (e.g., AMP, CAP, CLI, SMZ, TET, TYL, and VCM) were often detected in urban canals with median concentrations $<100 \mathrm{ng} / \mathrm{L}$. The concentrations of most detected antibiotics in urban canals sometimes exceeded or was close to their PNEC $_{\mathrm{AMR}}$ for antibiotic resistance selection or PNEC $_{\text {Ecotox }}$ for ecological toxicity to aquatic organisms. Similarly, macrolides (AZT, CLAR, ERY, and ERY- $\mathrm{H}_{2} \mathrm{O}$ ), fluoroquinolones (ENFLX and OFLX), lincosamides (CLI and LIN), sulfonamides (SMX and SMZ) and trimethoprim (TMP) were frequently detected in urban lakes, while other classes such as beta-lactams and tetracyclines were rarely found. The highest concentration of several antibiotics (AMX, CIPX, CLAR, ENFLX, ERY, and OFLX) in urban lakes was above PNEC $_{\text {AMR }}$ for antibiotic resistance selection, and significantly higher than $\mathrm{PNEC}_{\mathrm{Ecotox}}$ for aquatic organisms. The concentration and detection frequency of most antibiotics in surface waters in Hanoi were higher than those of developed countries (North America, Europe and Japan). Further studies to reveal the occurrence of antibiotic resistance bacteria (ARB) and antibiotic resistance genes (ARGs) in urban canals and lakes are recommended.

\section{Acknowledgement}

This research grant is partially supported by the Singapore National Research Foundation (NRF) under its Campus for Research Excellence and Technological Enterprise (CREATE) programme (E2S2-CREATE project ES-2: Detection, Assessment \& Modelling of Emerging Contaminants in the Urban Environment). We also thank the National University of Singapore Environmental Institute (NERI) for administrative support.

\section{References}

Agunbiade FO, Moodley B. Occurrence and distribution pattern of acidic pharmaceuticals in surface water, wastewater, and sediment of the Msunduzi River, Kwazulu-Natal, South Africa. Environ. Toxicol. Chem. 2016; 35: 36-46.

Al Aukidy M, Verlicchi P, Jelic A, Petrovic M, Barcelo D. Monitoring release of pharmaceutical compounds: occurrence and environmental risk assessment of two WWTP effluents and their receiving bodies in the Po Valley, Italy. Sci Total Environ 2012; 438: 15-25. 
Al Aukidy M, Verlicchi P, Voulvoulis N. A framework for the assessment of the environmental risk posed by pharmaceuticals originating from hospital effluents. Sci .Total Environ. 2014; 493: 54-64.

Ando T, Nagase H, Eguchi K, Hirooka T, et al. A novel method using cyanobacteria for ecotoxicity test of veterinary antimicrobial agents. Environ. Toxicol. Chem. 2007; 26: 601-6.

Andreozzi R, Caprio V, Ciniglia C, de Champdoré M, Lo Giudice R, Marotta R, et al. Antibiotics in the environment: occurrence in Italian STPs, fate, and preliminary assessment on algal toxicity of amoxicillin. Environ. Sci. Technol. 2004; 38: 6832-6838.

aus der Beek T, Weber FA, Bergmann A, Hickmann S, Ebert I, Hein A, et al. Pharmaceuticals in the environment-Global occurrences and perspectives. Environ. Toxicol. Chem. 2016; 35: 823-35.

Azanu D, Styrishave B, Darko G, Weisser JJ, Abaidoo RC. Occurrence and risk assessment of antibiotics in water and lettuce in Ghana. Sci Total Environ 2018; 622-623: 293-305.

Backhaus T, Grimme LH. The toxicity of antibiotic agents to the luminescent bacterium Vibrio fischeri. Chemosphere 1999; 38: 3291-3301.

Behera SK, Kim HW, Oh JE, Park HS. Occurrence and removal of antibiotics, hormones and several other pharmaceuticals in wastewater treatment plants of the largest industrial city of Korea. Sci. Total Environ. 2011; 409: 4351-60.

Ben Y, Fu C, Hu M, Liu L, Wong MH, Zheng C. Human health risk assessment of antibiotic resistance associated with antibiotic residues in the environment: A review. Environ. Res. 2019; 169: 483-493.

Bengtsson-Palme J, Larsson DGJ. Concentrations of antibiotics predicted to select for resistant bacteria: proposed limits for environmental regulation. Environ. Int. 2016; 86.

Bielen A, Simatovic A, Kosic-Vuksic J, Senta I, Ahel M, Babic S, et al. Negative environmental impacts of antibiotic-contaminated effluents from pharmaceutical industries. Water Res 2017; 126: 79-87. 
Blair JM, Webber MA, Baylay AJ, Ogbolu DO, Piddock LJ. Molecular mechanisms of antibiotic resistance. Nat. Rev. Microbiol. 2015; 13: 42-51.

Brixham Laboratory U. Meropenem: Determination of toxicity to the blue-green alga, Anabena flos-aquae. Brixham Environmental Laboratory, UK. Report No BR0530/B. 2011.

Burke V, Richter D, Greskowiak J, Mehrtens A, Schulz L, Massmann G. Occurrence of antibiotics in surface and groundwater of a drinking water catchment area in Germany. Water Environ. Res. 2016; 88: 652-659.

Carlotti B, Cesaretti A, Elisei F. Complexes of tetracyclines with divalent metal cations investigated by stationary and femtosecond-pulsed techniques. Phys. Chem. Chem. Phys. 2012; 14: 823-834.

Cha J, Cupples AM. Detection of the antimicrobials triclocarban and triclosan in agricultural soils following land application of municipal biosolids. Water Res. 2009; 43: 2522-30.

Cha JM, Yang S, Carlson KH. Trace determination of beta-lactam antibiotics in surface water and urban wastewater using liquid chromatography combined with electrospray tandem mass spectrometry. J. Chromatogr. A 2006; 1115: 46-57.

Chen Y, Hu C, Qu J, Yang M. Photodegradation of tetracycline and formation of reactive oxygen species in aqueous tetracycline solution under simulated sunlight irradiation. J. Photochem. Photobiol. A 2008; 197: 81-87.

Chen Y, Chen H, Zhang L, Jiang Y, Gin K, He Y. Occurrence, distribution, and risk assessment of antibiotics in a subtropical river-reservoir system. Water 2018; 10: 104.

Choi K, Kim Y, Jung J, Kim M-H, Kim C-S, Kim N-H, et al. Occurrences and ecological risks of roxithromycin, trimethoprim, and chloramphenicol in the Han river, Korea Environ. Toxicol. Chem. 2008; 27: 711-9.

Díaz-Cruz MS, Barceló D. LC-MS² trace analysis of antimicrobials in water, sediment and soil. TrAC-Trend. Anal. Chem. 2005; 24: 645-657. 
Dinh QT, Alliot F, Moreau-Guigon E, Eurin J, Chevreuil M, Labadie P. Measurement of trace levels of antibiotics in river water using on-line enrichment and triple-quadrupole LC-MS/MS. Talanta 2011; 85: 1238-1245.

Dinh QT, Moreau-Guigon E, Labadie P, Alliot F, Teil M-J, Blanchard M, et al. Occurrence of antibiotics in rural catchments. Chemosphere 2017; 168: 483-490.

Drury B, Scott J, Rosi-Marshall EJ, Kelly JJ. Triclosan exposure increases triclosan resistance and influences taxonomic composition of benthic bacterial communities. Environ Sci Technol 2013; 47: 8923-30.

Duong HA, Pham NH, Nguyen HT, Hoang TT, Pham HV, Pham VC, et al. Occurrence, fate and antibiotic resistance of fluoroquinolone antibacterials in hospital wastewaters in Hanoi, Vietnam. Chemosphere 2008; 72: 968-973.

EC. Technical guidance document on risk assessment, (TGD). Part II, Technical Report, Institute for Health and Consumer Protection, European Chemicals Bureau, European Commission (EC). 2003.

Ferrari B, Mons R, Vollat B, Fraysse B, Paxēaus N, Giudice RL, et al. Environmental risk assessment of six human pharmaceuticals: Are the current environmental risk assessment procedures sufficient for the protection of the aquatic environment? Environ. Toxicol. Chem. 2004; 23: 1344-1354.

Forsberg KJ, Reyes A, Wang B, Selleck EM, Sommer MO, Dantas G. The shared antibiotic resistome of soil bacteria and human pathogens. Science 2012; 337.

Gao P, Munir M, Xagoraraki I. Correlation of tetracycline and sulfonamide antibiotics with corresponding resistance genes and resistant bacteria in a conventional municipal wastewater treatment plant. Sci Total Environ 2012; 421-422: 173-83.

Gobel A, Thomsen A, McArdell CS, Joss A, Giger W. Occurrence and sorption behavior of sulfonamides, macrolides, and trimethoprim in activated sludge treatment. Environ. Sci. Technol. 2005; 39: 3981-3989. 
Gobel A, McArdell CS, Joss A, Siegrist H, Giger W. Fate of sulfonamides, macrolides, and trimethoprim in different wastewater treatment technologies. Sci. Total Environ. 2007; 372: 361-71.

Gonzalez-Pleiter M, Gonzalo S, Rodea-Palomares I, Leganes F, Rosal R, Boltes K, et al. Toxicity of five antibiotics and their mixtures towards photosynthetic aquatic organisms: implications for environmental risk assessment. Water Res 2013; 47: 2050-64.

Gozlan I, Rotstein A, Avisar D. Investigation of an amoxicillin oxidative degradation product formed under controlled environmental conditions. Environ. Chem. 2010; 7: 435-442.

Gracia-Lor E, Sancho JV, Serrano R, Hernandez F. Occurrence and removal of pharmaceuticals in wastewater treatment plants at the Spanish Mediterranean area of Valencia. Chemosphere 2012; 87: 453-62.

Graham DW, Knapp CW, Christensen BT, McCluskey S, Dolfing J. Appearance of $\beta$-lactam resistance genes in agricultural soils and clinical isolates over the 20th century. Sci Rep 2016; 6.

Guerra P, Kim M, Shah A, Alaee M, Smyth SA. Occurrence and fate of antibiotic, analgesic/antiinflammatory, and antifungal compounds in five wastewater treatment processes. Sci Total Environ 2014; 473-474: 235-43.

Gulkowska A, Leung HW, So MK, Taniyasu S, Yamashita N, Yeung LW, et al. Removal of antibiotics from wastewater by sewage treatment facilities in Hong Kong and Shenzhen, China. Water Res 2008; 42: 395-403.

Gurke R, Rossler M, Marx C, Diamond S, Schubert S, Oertel R, et al. Occurrence and removal of frequently prescribed pharmaceuticals and corresponding metabolites in wastewater of a sewage treatment plant. Sci. Total Environ. 2015; 532: 762-70.

Halling-Sørensen B, Ingerslev F, Andersen HR, Lützhøft H-CH. Environmental risk assessment of antibiotics: comparison of mecillinam, trimethoprim and ciprofloxacin. Journal of Antimicrobial Chemotherapy 2000; 46: 53-58. 
Hanna N, Sun P, Sun Q, Li X, Yang X, Ji X, et al. Presence of antibiotic residues in various environmental compartments of Shandong province in eastern China: Its potential for resistance development and ecological and human risk. Environ Int 2018; 114: 131-142.

Harrabi M, Varela Della Giustina S, Aloulou F, Rodriguez-Mozaz S, Barceló D, Elleuch B. Analysis of multiclass antibiotic residues in urban wastewater in Tunisia. Environmental Nanotechnology, Monitoring \& Management 2018; 10: 163-170.

Havelkova B, Beklova M, Kovacova V, Hlavkova D, Pikula J. Ecotoxicity of selected antibiotics for organisms of aquatic and terrestrial ecosystems. Neuroendocrinology Letters 2016; 137: $38-44$.

Hirsch R, Ternes T, Haberer K, Kratz K-L. Occurrence of antibiotics in the aquatic environment. Sci .Total Environ. 1999; 225: 109-118.

Hirte K, Seiwert B, Schuurmann G, Reemtsma T. New hydrolysis products of the beta-lactam antibiotic amoxicillin, their pH-dependent formation and search in municipal wastewater. Water Res. 2016; 88: 880-8.

Hoai NT, Dang T. The determinants of self-medication: Evidence from urban Vietnam. Soc Work Health Care 2017; 56: 260-282.

Holmes NE, Tong SY, Davis JS, van Hal SJ. Treatment of methicillin-resistant Staphylococcus aureus: vancomycin and beyond. Semin Respir Crit Care Med 2015; 36: 17-30.

Huang M-h, Yang Y-d, Chen D-h, Chen L, Guo H-d. Removal mechanism of trace oxytetracycline by aerobic sludge. Process Safety and Environmental Protection 2012; 90: 141-146.

Huong NTL, Masami 0, Li L, Higashi T, Kanayama M. Heavy metal contamination of river sediments in Vietnam. Proceedings of the Institution of Civil Engineers - Water Management 2010; 163: 111-121.

Isidori M, Lavorgna M, Nardelli A, Pascarella L, Parrella A. Toxic and genotoxic evaluation of six antibiotics on non-target organisms. Sci. Total Environ. 2005; 346: 87-98.

Jiang L, Hu X, Yin D, Zhang H, Yu Z. Occurrence, distribution and seasonal variation of antibiotics in the Huangpu River, Shanghai, China. Chemosphere 2011; 82: 822-8. 
Jong MC, Su JQ, Bunce JT, Harwood CR, Snape JR, Zhu YG, et al. Co-optimization of sponge-core bioreactors for removing total nitrogen and antibiotic resistance genes from domestic wastewater. Sci Total Environ 2018; 634: 1417-1423.

Kafaei R, Papari F, Seyedabadi M, Sahebi S, Tahmasebi R, Ahmadi M, et al. Occurrence, distribution, and potential sources of antibiotics pollution in the water-sediment of the northern coastline of the Persian Gulf, Iran. Sci Total Environ 2018; 627: 703-712.

Karthikeyan KG, Meyer MT. Occurrence of antibiotics in wastewater treatment facilities in Wisconsin, USA. Sci.Total Environ. 2006; 361: 196-207.

Kasprzyk-Hordern B, Dinsdale RM, Guwy AJ. The occurrence of pharmaceuticals, personal care products, endocrine disruptors and illicit drugs in surface water in South Wales, UK. Water Res. 2008; 42: 3498-3518.

Kasprzyk-Hordern B, Dinsdale RM, Guwy AJ. The removal of pharmaceuticals, personal care products, endocrine disruptors and illicit drugs during wastewater treatment and its impact on the quality of receiving waters. Water Res 2009; 43: 363-80.

Kemmerich B, Warns H, Lode H, Borner K, Koeppe P, Knothe H. Multiple-dose pharmacokinetics of ceftazidime and its influence on fecal flora. Antimicrob Agents Chemother 1983; 24: 333-8.

Khan GA, Berglund B, Khan KM, Lindgren PE, Fick J. Occurrence and abundance of antibiotics and resistance genes in rivers, canal and near drug formulation facilities--a study in Pakistan. PLoS One 2013; 8: e62712.

Kibuye FA, Gall HE, Elkin KR, Ayers B, Veith TL, Miller M, et al. Fate of pharmaceuticals in a sprayirrigation system: From wastewater to groundwater. Sci .Total Environ. 2019; 654: 197208.

Kim S, Aga DS. Potential ecological and human health impacts of antibiotics and antibioticresistant bacteria from wastewater treatment plants. J. Toxicol. Environ. Health B Crit. Rev. 2007; 10: 559-73. 
Knapp CW, Dolfing J, Ehlert PA, Graham DW. Evidence of increasing antibiotic resistance gene abundances in archived soils since 1940. Environ. Sci. Technol. 2010; 44.

Koike S, Aminov RI, Yannarell AC, Gans HD, Krapac IG, Chee-Sanford JC, et al. Molecular ecology of macrolide-lincosamide-streptogramin B methylases in waste lagoons and subsurface waters associated with swine production. Microbial Ecology 2010; 59: 487-498.

Kosma CI, Lambropoulou DA, Albanis TA. Occurrence and removal of PPCPs in municipal and hospital wastewaters in Greece. J. Hazard. Mater. 2010; 179: 804-817.

Kreuzinger N, Clara M, Strenn B, Vogel B. Investigation on the behaviour of selected pharmaceuticals in the groundwater after infiltration of treated wastewater. Water Sci. Technol. 2004; 50: 221-8.

Kummerer K. Antibiotics in the aquatic environment-a review-part I. Chemosphere 2009; 75: 417-34.

Kümmerer K, Henninger A. Promoting resistance by the emission of antibiotics from hospitals and households into effluent. Clin. Microbiol. Infect. 2003; 9: 1203-1214.

Lamba M, Gupta S, Shukla R, Graham DW, Sreekrishnan TR, Ahammad SZ. Carbapenem resistance exposures via wastewaters across New Delhi. Environ Int 2018; 119: 302-308.

Le-Minh N, Khan SJ, Drewes JE, Stuetz RM. Fate of antibiotics during municipal water recycling treatment processes. Water Res. 2010; 44: 4295-323.

Le TH, Ng C, Tran NH, Chen H, Gin KY. Removal of antibiotic residues, antibiotic resistant bacteria and antibiotic resistance genes in municipal wastewater by membrane bioreactor systems. Water Res 2018; 145: 498-508.

Le TX, Munekage Y. Residues of selected antibiotics in water and mud from shrimp ponds in mangrove areas in Viet Nam. Mar Pollut Bull 2004; 49: 922-9.

Li XW, Xie YF, Li CL, Zhao HN, Zhao H, Wang N, et al. Investigation of residual fluoroquinolones in a soil-vegetable system in an intensive vegetable cultivation area in Northern China. Sci Total Environ 2014; 468-469: 258-64. 
Lillicrap A. Ceftizidime hydrochloride: Toxicity to the blue green alga, Anabaena flos-aquae. Report No. BL7723/B . Brixham Environmental Laboratories. 2004.

Luo Y, Guo W, Ngo HH, Nghiem LD, Hai FI, Zhang J, et al. A review on the occurrence of micropollutants in the aquatic environment and their fate and removal during wastewater treatment. Sci. Total Environ. 2014; 473-474: 619-641.

Lützhøft HCH, Halling-Sørensen B, Jørgensen SE. Algal toxicity of antibacterial agents applied in Danish fish farming. Arch. Environ. Contam. Toxicol. 1999; 36:1-6.

Martinez JL. The role of natural environments in the evolution of resistance traits in pathogenic bacteria. Proc. Biol. Sci. 2009; 276: 2521-2530.

Matsuo H, Sakamoto H, Arizono K, Shinohara R. Behavior of pharmaceuticals in wastewater treatment plant in Japan. Bulletin of Environmental Contamination and Toxicology 2011; 87: 31-35.

Miao XS, Bishay F, Chen M, Metcalfe CD. Occurrence of antimicrobials in the final effluents of wastewater treatment plants in Canada. Environ. Sci. Technol. 2004; 38: 3533-41.

Miège C, Choubert JM, Ribeiro L, Eusèbe M, Coquery M. Fate of pharmaceuticals and personal care products in wastewater treatment plants - conception of a database and first results. Environ. Pollut. 2009; 157: 1721-1726.

Minguez L, Pedelucq J, Farcy E, Ballandonne C, Budzinski H, Halm-Lemeille MP. Toxicities of 48 pharmaceuticals and their freshwater and marine environmental assessment in northwestern France. Environ Sci Pollut Res Int 2016; 23: 4992-5001.

Minh TB, Leung HW, Loi IH, Chan WH, So MK, Mao JQ, et al. Antibiotics in the Hong Kong metropolitan area: Ubiquitous distribution and fate in Victoria Harbour. Mar Pollut Bull 2009; 58: 1052-62.

Mirzaei R, Yunesian M, Nasseri S, Gholami M, Jalilzadeh E, Shoeibi S, et al. An optimized SPE-LCMS/MS method for antibiotics residue analysis in ground, surface and treated water samples by response surface methodology- central composite design. J Environ Health Sci Eng 2017; 15: 21. 
Mirzaei R, Yunesian M, Nasseri S, Gholami M, Jalilzadeh E, Shoeibi S, et al. Occurrence and fate of most prescribed antibiotics in different water environments of Tehran, Iran. Sci .Total Environ. 2018; 619-620: 446-459.

Mohapatra S, Huang CH, Mukherji S, Padhye LP. Occurrence and fate of pharmaceuticals in WWTPs in India and comparison with a similar study in the United States. Chemosphere 2016; 159: 526-35.

Nga DTT, Chuc NTK, Hoa NP, Hoa NQ, Nguyen NTT, Loan HT, et al. Antibiotic sales in rural and urban pharmacies in northern Vietnam: an observational study. BMC pharmacology \& toxicology 2014; 15: 6-6.

Nguyen DCG, Sebesvari Z, Renaud F, Rosendahl I, Hoang MQ, Amelung W. Occurrence and dissipation of the antibiotics sulfamethoxazole, sulfadiazine, trimethoprim, and enrofloxacin in the Mekong Delta, Vietnam. PLoS One 2015; 10: e0131855.

Nguyen KV, Thi Do NT, Chandna A, Nguyen TV, Pham CV, Doan PM, et al. Antibiotic use and resistance in emerging economies: a situation analysis for Viet Nam. BMC Public Health 2013; 13: 1158-1158.

Pailler JY, Krein A, Pfister L, Hoffmann L, Guignard C. Solid phase extraction coupled to liquid chromatography-tandem mass spectrometry analysis of sulfonamides, tetracyclines, analgesics and hormones in surface water and wastewater in Luxembourg. Sci Total Environ 2009; 407: 4736-43.

Palmer PM, Wilson LR, O'Keefe P, Sheridan R, King T, Chen CY. Sources of pharmaceutical pollution in the New York City Watershed. Sci Total Environ 2008; 394: 90-102.

Pan M, Wong CK, Chu LM. Distribution of antibiotics in wastewater-irrigated soils and their accumulation in vegetable crops in the Pearl River Delta, southern China. J Agric Food Chem 2014; 62: 11062-9.

Papageorgiou M, Kosma C, Lambropoulou D. Seasonal occurrence, removal, mass loading and environmental risk assessment of 55 pharmaceuticals and personal care products in a 
municipal wastewater treatment plant in Central Greece. Sci Total Environ 2016; 543: 547-69.

Peng X, Wang Z, Kuang W, Tan J, Li K. A preliminary study on the occurrence and behavior of sulfonamides, ofloxacin and chloramphenicol antimicrobials in wastewaters of two sewage treatment plants in Guangzhou, China. Sci Total Environ 2006; 371: 314-22.

Phan TPH, Managaki S, Nakada N, Takada H, Shimizu A, Duong HA, et al. Antibiotic contamination and occurrence of antibiotic-resistant bacteria in aquatic environments of northern Vietnam. Sci Total Environ 2011; 409: 2894-901.

Phillips P, Chalmers A. Wastewater effluent, combined sewer overflows, and other sources of oganic compounds to lake champlain. Journal of the American Water Resources Association 2009; 45: 45-57.

Richardson SD, Ternes TA. Water analysis: emerging contaminants and current issues. Anal. Chem. 2011; 83: 4614-4648.

Riva F, Zuccato E, Davoli E, Fattore E, Castiglioni S. Risk assessment of a mixture of emerging contaminants in surface water in a highly urbanized area in Italy. J. Hazard. Mater. 2019; 361: 103-110.

Rizzo L, Manaia C, Merlin C, Schwartz T, Dagot C, Ploy MC, et al. Urban wastewater treatment plants as hotspots for antibiotic resistant bacteria and genes spread into the environment: a review. Sci. Total Environ. 2013; 447: 345-60.

Robinson AA, Belden JB, Lydy MJ. Toxicity of fluoroquinolone antibiotics to aquatic organisms. Environ. Toxicol. Chem. 2005; 24: 423-430.

Rodriguez-Mozaz S, Chamorro S, Marti E, Huerta B, Gros M, Sànchez-Melsió A, et al. Occurrence of antibiotics and antibiotic resistance genes in hospital and urban wastewaters and their impact on the receiving river. Water Res. 2015; 69: 234-242.

Rodríguez DC, Ahammad ZS, Peñuela GA, Graham DW. Effect of $\beta$-lactamases associated to the resistance of $\beta$-lactam antibiotics on the treatment of wastewater. J. Environ. Chem. Eng. 2018. 
Schwartz T, Kohnen W, Jansen B, Obst U. Detection of antibiotic-resistant bacteria and their resistance genes in wastewater, surface water, and drinking water biofilms. FEMS Microbiol. Ecol. 2003; 43: 325-335.

Shimizu A, Takada H, Koike T, Takeshita A, Saha M, Rinawati, et al. Ubiquitous occurrence of sulfonamides in tropical Asian waters. Sci. Total Environ. 2013; 452-453: 108-115.

Song J-H, Jung S-I, Ko KS, Kim NY, Son JS, Chang H-H, et al. High prevalence of antimicrobial resistance among clinical Streptococcus pneumonia isolates in Asia (an ANSORP study). Antimicrobial Agents and Chemotherapy 2004; 48: 2101-2107.

Stoichev T, Baptista MS, Basto MCP, Vasconcelos VM, Vasconcelos MTSD. Effects of minocycline and its degradation products on the growth of Microcystis aeruginosa. Ecotoxicol Environ Saf 2011; 74: 219-224.

Subedi B, Balakrishna K, Sinha RK, Yamashita N, Balasubramanian VG, Kannan K. Mass loading and removal of pharmaceuticals and personal care products, including psychoactive and illicit drugs and artificial sweeteners, in five sewage treatment plants in India. J. Environ. Chem. Eng. 2015; 3: 2882-2891.

Sui Q, Huang J, Deng S, Chen W, Yu G. Seasonal variation in the occurrence and removal of pharmaceuticals and personal care products in different biological wastewater treatment processes. Environ. Sci. Technol. 2011; 45: 3341-3348.

Sun Q, Li M, Ma C, Chen X, Xie X, Yu CP. Seasonal and spatial variations of PPCP occurrence, removal and mass loading in three wastewater treatment plants located in different urbanization areas in Xiamen, China. Environ Pollut 2016; 208: 371-81.

Thai PK, Ky LX, Binh VN, Nhung PH, Nhan PT, Hieu NQ, et al. Occurrence of antibiotic residues and antibiotic-resistant bacteria in effluents of pharmaceutical manufacturers and other sources around Hanoi, Vietnam. Sci Total Environ 2018; 645: 393-400.

Timm A, Borowska E, Majewsky M, Merel S, Zwiener C, Bräse S, et al. Photolysis of four $\beta$ - lactam antibiotics under simulated environmental conditions: Degradation, transformation products and antibacterial activity. Sci .Total Environ. 2019; 651: 1605-1612. 
Tong L, Li P, Wang Y, Zhu K. Analysis of veterinary antibiotic residues in swine wastewater and environmental water samples using optimized SPE-LC/MS/MS. Chemosphere 2009; 74: 1090-7.

Tran NH, Urase T, Ta TT. A preliminary study on the occurrence of pharmaceutically active compounds in hospital wastewater and surface water in Hanoi, Vietnam. Clean: Soil, Air, Water 2014; 42: 267-275.

Tran NH, Chen H, Do TV, Reinhard M, Ngo HH, He Y, et al. Simultaneous analysis of multiple classes of antimicrobials in environmental water samples using SPE coupled with UHPLCESI-MS/MS and isotope dilution. Talanta 2016a; 159: 163-173.

Tran NH, Chen H, Reinhard M, Mao F, Gin KY-H. Occurrence and removal of multiple classes of antibiotics and antimicrobial agents in biological wastewater treatment processes. Water Res. 2016b; 104: 461-472.

Tran NH, Reinhard M, Gin KY-H. Occurrence and fate of emerging contaminants in municipal wastewater treatment plants from different geographical regions-a review. Water Res. 2018; 133: 182-207.

Tran NH, Reinhard M, Khan E, Chen H, Nguyen VT, Li Y, et al. Emerging contaminants in wastewater, stormwater runoff, and surface water: Application as chemical markers for diffuse sources. Sci .Total Environ. 2019; 676: 252-267.

van der Grinten E, Pikkemaat MG, van den Brandhof E-J, Stroomberg GJ, Kraak MHS. Comparing the sensitivity of algal, cyanobacterial and bacterial bioassays to different groups of antibiotics. Chemosphere 2010; 80: 1-6.

Verlicchi P, Galletti A, Petrovic M, Barceló D. Hospital effluents as a source of emerging pollutants: An overview of micropollutants and sustainable treatment options. Journal of Hydrology 2010; 389: 416-428.

Verlicchi P, Al Aukidy M, Zambello E. Occurrence of pharmaceutical compounds in urban wastewater: removal, mass load and environmental risk after a secondary treatment-a review. Sci. Total Environ. 2012; 429: 123-55. 
Watkinson AJ, Murby EJ, Costanzo SD. Removal of antibiotics in conventional and advanced wastewater treatment: Implications for environmental discharge and wastewater recycling. Water Res. 2007; 41: 4164-4176.

Watkinson AJ, Murby EJ, Kolpin DW, Costanzo SD. The occurrence of antibiotics in an urban watershed: from wastewater to drinking water. Sci Total Environ 2009; 407: 2711-23.

Yang L-H, Ying G-G, Su H-C, Stauber JL, Adams MS, Binet MT. Growth-inhibiting effects of 12 antibacterial agents and their mixtures on the freshwater microalga Pseudokirchneriella subcapitata. Environ. Toxicol. Chem. 2008; 27: 1201-1208.

Yang Y-Y, Liu W-R, Liu Y-S, Zhao J-L, Zhang Q-Q, Zhang M, et al. Suitability of pharmaceuticals and personal care products (PPCPs) and artificial sweeteners (ASs) as wastewater indicators in the Pearl River Delta, South China. Sci .Total Environ. 2017; 590-591: 611-619.

Zaranyika MF, Dzomba P, Kugara J. Degradation of oxytetracycline in the aquatic environment: a proposed steady state kinetic model that takes into account hydrolysis, photolysis, microbial degradation and adsorption by colloidal and sediment particles. Environ. Chem. $2015 ; 12: 174$.

Zhang X, Li Y, Liu B, Wang J, Feng C, Gao M, et al. Prevalence of veterinary antibiotics and antibiotic-resistant Escherichia coli in the surface water of a livestock production region in northern China. PLoS One 2014; 9: e111026.

Zhao S, Liu X, Cheng D, Liu G, Liang B, Cui B, et al. Temporal-spatial variation and partitioning prediction of antibiotics in surface water and sediments from the intertidal zones of the Yellow River Delta, China. Sci Total Environ 2016; 569-570: 1350-1358.

Zhi S, Zhou J, Yang F, Tian L, Zhang K. Systematic analysis of occurrence and variation tendency about 58 typical veterinary antibiotics during animal wastewater disposal processes in Tianjin, China. Ecotoxicol Environ Saf 2018; 165: 376-385.

Zhou H, Ying T, Wang X, Liu J. Occurrence and preliminarily environmental risk assessment of selected pharmaceuticals in the urban rivers, China. Scientific Reports 2016; 6: 34928. 
Zhou L-J, Ying G-G, Liu S, Zhao J-L, Chen F, Zhang R-Q, et al. Simultaneous determination of human and veterinary antibiotics in various environmental matrices by rapid resolution liquid chromatography-electrospray ionization tandem mass spectrometry. J. Chromatogr. A 2012; 1244: 123-138.

Zonja B, Perez S, Barcelo D. Human metabolite lamotrigine-N(2)-glucuronide is the principal source of lamotrigine-derived compounds in wastewater treatment plants and surface water. Environ Sci Technol 2016; 50: 154-64.

Zuccato E, Castiglioni S, Bagnati R, Melis M, Fanelli R. Source, occurrence and fate of antibiotics in the Italian aquatic environment. J Hazard Mater 2010; 179: 1042-8. 
Table 1. Method detection limit (MDL) and method quantification limit (MQL) for antibiotics in urban canal and lake samples.

\begin{tabular}{|c|c|c|c|c|}
\hline \multirow[t]{2}{*}{ Target antibiotics } & \multicolumn{2}{|c|}{ Urban lake samples } & \multicolumn{2}{|c|}{ Urban canal samples } \\
\hline & MDL (ng/L) & MQL (ng/L) & MDL (ng/L) & MQL (ng/L) \\
\hline AMP & 0.5 & 2.0 & 1.0 & 3.5 \\
\hline AMX & 15 & 50 & 25 & 80 \\
\hline AZT & 0.05 & 0.15 & 0.1 & 0.3 \\
\hline CAP & 0.4 & 1.3 & 0.5 & 1.5 \\
\hline CFEX & 0.15 & 0.5 & 0.3 & 1.0 \\
\hline CFZ & 20 & 60 & 30 & 100 \\
\hline CIPX & 0.4 & 1.5 & 0.8 & 2.5 \\
\hline CLAR & 0.05 & 0.15 & 0.2 & 0.8 \\
\hline CLI & 0.03 & 0.1 & 0.15 & 0.5 \\
\hline CTC & 1.0 & 3.5 & 2.0 & 6.0 \\
\hline ENFLX & 0.2 & 0.8 & 0.4 & 1.2 \\
\hline ERY & 0.1 & 0.4 & 0.3 & 0.9 \\
\hline $\mathrm{ERY}-\mathrm{H}_{2} \mathrm{O}$ & 0.1 & 0.4 & 0.15 & 0.5 \\
\hline LIN & 0.05 & & 0.08 & 0.25 \\
\hline MER & 2.0 & & 5.0 & 15 \\
\hline MIN & 12 & 35 & 40 & 125 \\
\hline OFLX & 0.3 & 1.0 & 0.5 & 1.5 \\
\hline OXY & 8.0 & 30 & 18 & 60 \\
\hline SMX & 0.1 & 0.4 & 0.15 & 0.5 \\
\hline SMZ & 0.05 & 0.15 & 0.1 & 0.3 \\
\hline TET & 6.0 & 20 & 10 & 40 \\
\hline TMP & 0.1 & 0.4 & 0.2 & 0.6 \\
\hline TYL & 0.2 & 0.8 & 0.4 & 1.5 \\
\hline VCM & 4.0 & 12 & 8.0 & 30 \\
\hline
\end{tabular}

AMX: amoxicillin; AMP: ampicillin; AZT: azithromycin; CAP: chloramphenicol; CEFX: cefixime; CFZ: ceftazidime; CIPX: ciprofloxacin; CLAR: clarithromycin; CLI: clindamycin; CTC: chlortetracycline; ENFLX: enrofloxacin; ERY: erythromycin; LIN: lincomycin; MER: meropenem; ERY- $\mathrm{H}_{2} \mathrm{O}$ : anhydroerythromycin; OFLX: ofloxacin; OXY: oxytetracycline; SMX: sulfamethoxazole; SMZ: sulfamethazine; TET: tetracycline; TMP: trimethoprim; TYL: tylosin; VCM: vancomycin. 
Table 2. Concentrations and detection frequency of antibiotics in wastewater from two urban canals in this study compared to the raw wastewater in other countries

\begin{tabular}{|c|c|c|c|c|c|c|}
\hline \multirow{2}{*}{$\begin{array}{l}\text { Target } \\
\text { antibiotics } \\
8\end{array}$} & \multicolumn{3}{|c|}{ In this study $(\mathrm{n}=28)$} & \multicolumn{3}{|c|}{ In other geographical regions } \\
\hline & $\begin{array}{l}\text { Range } \\
\text { (ng/L) }\end{array}$ & $\begin{array}{l}\text { Median } \\
\text { (ng/L) }\end{array}$ & $\begin{array}{l}\text { DF } \\
(\%)\end{array}$ & $\begin{array}{l}\text { Range } \\
\text { (ng/L) }\end{array}$ & Region & Reference \\
\hline \multirow[t]{3}{*}{ AMX } & $<\mathrm{MQL}-20,608$ & 3,162 & 89.3 & $<M Q L-6,516$ & Asia & (Minh et al., 2009; Tran et al., 2018) \\
\hline & & & & - & North America & (Palmer et al., 2008; Tran et al., 2018) \\
\hline & & & & $<\mathrm{MQL}-18$ & Europe & (Zuccato et al., 2010; Tran et al., 2018) \\
\hline \multirow[t]{3}{*}{ AMP } & $<$ MQL-357 & 71 & 67.9 & $<\mathrm{MQL}-4,340$ & Asia & (Zhi et al., 2018) \\
\hline & & & & $<M Q L-3,920.4$ & North America & (Kibuye et al., 2019) \\
\hline & & & & $<\mathrm{MQL}-1,805$ & Europe & (Papageorgiou et al., 2016) \\
\hline \multirow[t]{3}{*}{ AZT } & $4.9-3,766$ & 524 & 100 & $1,537-303,500$ & Asia & (Mohapatra et al., 2016; Tran et al., 2018) \\
\hline & & & & $61-2,500$ & North America & (Guerra et al., 2014; Tran et al., 2018) \\
\hline & & & & $77-1,139$ & Europe & (Gobel et al., 2007; Tran et al., 2018) \\
\hline \multirow[t]{3}{*}{ CAP } & $<\mathrm{MQL}-155$ & 57 & 96.4 & $<\mathrm{MQL}-2,430$ & Asia & (Minh et al., 2009; Tran et al., 2018) \\
\hline & & & & - & North America & (Tran et al., 2018) \\
\hline & & & & $<\mathrm{MQL}-319$ & Europe & (Tran et al., 2018) \\
\hline \multirow[t]{3}{*}{ CEFX } & $<\mathrm{MQL}$ & $<\mathrm{MQL}$ & 0 & $<\mathrm{MQL}-318.6$ & Asia & (Mirzaei et al., 2018) \\
\hline & & & & - & North America & - \\
\hline & & & & - & Europe & - \\
\hline \multirow[t]{3}{*}{ CFZ } & $<\mathrm{MQL}$ & $<\mathrm{MQL}$ & 0 & $<\mathrm{MQL}$ & Asia & (Tran et al., 2018) \\
\hline & & & & - & North America & (Tran et al., 2018) \\
\hline & & & & - & Europe & (Tran et al., 2018) \\
\hline \multirow[t]{3}{*}{ CIPX } & $<\mathrm{MQL}-3,035$ & 302 & 89.3 & $15.5-6,453$ & Asia & (Mohapatra et al., 2016; Tran et al., 2018) \\
\hline & & & & $<\mathrm{MQL}-246,100$ & North America & (Guerra et al., 2014; Tran et al., 2018) \\
\hline & & & & $<$ MQL-13,625 & Europe & (Tran et al., 2018) \\
\hline \multirow[t]{3}{*}{ CLAR } & $7-3,944$ & 700 & 100 & $26-1,854$ & Asia & (Tran et al., 2016b; Yang et al., 2017) \\
\hline & & & & $<\mathrm{MQL}-8,000$ & North America & (Guerra et al., 2014; Tran et al., 2018) \\
\hline & & & & $0.4-647$ & Europe & (Gobel et al., 2007; Tran et al., 2018) \\
\hline \multirow[t]{3}{*}{ CLI } & $6-29$ & 10 & 100 & $23.8-26.6$ & Asia & (Tran et al., 2018) \\
\hline & & & & - & North America & (Tran et al., 2018) \\
\hline & & & & $<\mathrm{MQL}-101$ & Europe & (Tran et al., 2018) \\
\hline \multirow[t]{3}{*}{ CTC } & $<\mathrm{MQL}$ & $<\mathrm{MO}$ & 0 & $2,333-15,911$ & Asia & (Minh et al., 2009; Tran et al., 2018) \\
\hline & & & & $<\mathrm{MQL}-310$ & North America & (Guerra et al., 2014; Tran et al., 2018) \\
\hline & & & & - & Europe & (Tran et al., 2018) \\
\hline \multirow[t]{3}{*}{ ENFLX } & $55-2,869$ & 226 & 100 & $<\mathrm{MQL}-1,690$ & Asia & (Zhi et al., 2018) \\
\hline & & & & $5.9-250$ & North America & (Guerra et al., 2014; Tran et al., 2018) \\
\hline & & & & $<\mathrm{MQL}-18$ & Europe & (Tran et al., 2018) \\
\hline \multirow[t]{3}{*}{ ERY } & $<\mathrm{MQL}-48,517$ & 5,542 & 67.9 & $111.4-403.3$ & Asia & (Tran et al., 2018) \\
\hline & & & & - & North America & (Tran et al., 2018) \\
\hline & & & & $<\mathrm{MQL}-2,130$ & Europe & (Miège et al., 2009; Tran et al., 2018) \\
\hline \multirow[t]{3}{*}{$\mathrm{ERY}-\mathrm{H}_{2} \mathrm{O}$} & $6-2,141$ & 581 & 100 & $226-20,600$ & Asia & (Minh et al., 2009; Tran et al., 2018) \\
\hline & & & & $<\mathrm{MQL}-3,900$ & North America & (Guerra et al., 2014; Tran et al., 2018) \\
\hline & & & & $24-6,755$ & Europe & (Gobel et al., 2007; Tran et al., 2018) \\
\hline
\end{tabular}


Table 2. Continued.

\begin{tabular}{|c|c|c|c|c|c|c|}
\hline \multirow{2}{*}{$\begin{array}{l}\text { Target } \\
\text { ABs }\end{array}$} & \multicolumn{3}{|c|}{ In this study $(n=28)$} & \multicolumn{3}{|c|}{ In other countries } \\
\hline & $\begin{array}{l}\text { Range } \\
\text { (ng/L) }\end{array}$ & $\begin{array}{l}\text { Median } \\
\text { (ng/L) }\end{array}$ & $\begin{array}{l}\text { DF } \\
(\%)\end{array}$ & $\begin{array}{l}\text { Range } \\
\text { (ng/L) }\end{array}$ & Region & Reference \\
\hline \multirow[t]{3}{*}{ LIN } & $67-1,968$ & 952 & 100 & $<$ MQL-19,401 & Asia & (Tran et al., 2016b; Tran et al., 2018) \\
\hline & & & & $<\mathrm{MQL}-360$ & North America & (Guerra et al., 2014; Tran et al., 2018) \\
\hline & & & & $<$ MQL-281 & Europe & (Tran et al., 2018) \\
\hline \multirow[t]{3}{*}{ MER } & $<\mathrm{MQL}$ & $<\mathrm{MQL}$ & 0 & $264.8-433.6$ & Asia & (Tran et al., 2018) \\
\hline & & & & - & North America & (Tran et al., 2018) \\
\hline & & & & - & Europe & (Tran et al., 2018) \\
\hline \multirow[t]{3}{*}{ MIN } & $<\mathrm{MQL}$ & $<\mathrm{MQL}$ & 0 & $730.9-3,808$ & Asia & (Tran et al., 2016b; Tran et al., 2018) \\
\hline & & & & - & North America & (Guerra et al., 2014; Tran et al., 2018) \\
\hline & & & & - & Europe & (Tran et al., 2018) \\
\hline \multirow[t]{3}{*}{ OFLX } & $45-2,867$ & 272 & 100 & $54.8-1,274$ & Asia & (Minh et al., 2009; Tran et al., 2018) \\
\hline & & & & $470-1,000$ & North America & (Guerra et al., 2014; Tran et al., 2018) \\
\hline & & & & - & Europe & (Dinh et al., 2017; Tran et al., 2018) \\
\hline \multirow[t]{3}{*}{ OXY } & $<\mathrm{MQL}-116$ & $<\mathrm{MQL}$ & 25 & $<$ MQL-30,049 & Asia & (Minh et al., 2009; Tran et al., 2018) \\
\hline & & & & $<$ MQL-47,000 & North America & (Guerra et al., 2014; Tran et al., 2018) \\
\hline & & & & $<\mathrm{MQL}-7$ & Europe & (Pailler et al., 2009; Tran et al., 2018) \\
\hline \multirow[t]{3}{*}{ SMX } & $310-15,591$ & 7,631 & 100 & $3.0-1,389$ & Asia & (Minh et al., 2009; Tran et al., 2018) \\
\hline & & & & $<\mathrm{MQL}-4,200$ & North America & (Guerra et al., 2014; Tran et al., 2018) \\
\hline & & & & $<$ MQL-11,555 & Europe & (Tran et al., 2018) \\
\hline \multirow[t]{3}{*}{ SMZ } & $<\mathrm{MQL}-128$ & 53 & 92.9 & $<\mathrm{MQL}-1,814$ & Asia & (Minh et al., 2009; Tran et al., 2018) \\
\hline & & & & $<\mathrm{MQL}-300$ & North America & (Guerra et al., 2014; Tran et al., 2018) \\
\hline & & & & $<M Q L-680$ & Europe & (Miège et al., 2009; Tran et al., 2018) \\
\hline \multirow[t]{3}{*}{ TET } & $<M Q L-635$ & 101 & 92.9 & $<\mathrm{MQL}-12,340$ & Asia & (Minh et al., 2009; Tran et al., 2018) \\
\hline & & & & $<$ MQL-48,000 & North America & (Guerra et al., 2014; Tran et al., 2018) \\
\hline & & & & $<M Q L-790$ & Europe & (Tran et al., 2018) \\
\hline \multirow[t]{3}{*}{ TMP } & $48-853$ & 256 & 100 & $19.5-570$ & Asia & (Gulkowska et al., 2008; Tran et al., 2018) \\
\hline & & & & $<$ MQL-6,796 & North America & (Guerra et al., 2014; Tran et al., 2018) \\
\hline & & & & $<\mathrm{MQL}-4,342$ & Europe & (Gobel et al., 2007; Tran et al., 2018) \\
\hline \multirow[t]{3}{*}{ TYL } & $<$ MQL-692 & 28 & 75 & $<\mathrm{MQL}$ & Asia & (Minh et al., 2009; Tran et al., 2018) \\
\hline & & & & $<\mathrm{MQL}-1,500$ & North America & (Guerra et al., 2014; Tran et al., 2018) \\
\hline & & & & $<\mathrm{MQL}$ & Europe & (Tran et al., 2018) \\
\hline \multirow[t]{3}{*}{ VCM } & $<\mathrm{MQL}-249$ & 25 & 71.4 & $962-43,740$ & Asia & (Tran et al., 2016b; Tran et al., 2018) \\
\hline & & & & - & North America & (Tran et al., 2018) \\
\hline & & & & - & Europe & (Dinh et al., 2017; Tran et al., 2018) \\
\hline
\end{tabular}

DF: detection frequency; MQL: method quantification limit; -: not available in the literature; 
Table 3. Concentrations and detection frequency of antibiotics in urban lakes in this study compared to that in surface waters from other countries.

\begin{tabular}{|c|c|c|c|c|c|c|c|}
\hline \multirow{2}{*}{$\begin{array}{l}\text { Target } \\
\text { ABs }\end{array}$} & \multicolumn{3}{|c|}{ In this study $(\mathrm{n}=25)$} & \multicolumn{4}{|c|}{ From the previous literature } \\
\hline & $\begin{array}{l}\text { Range } \\
\text { (ng/L) }\end{array}$ & $\begin{array}{l}\text { Median } \\
(\mathrm{ng} / \mathrm{L})\end{array}$ & $\begin{array}{l}\text { DF } \\
(\%)\end{array}$ & $\begin{array}{l}\text { Range } \\
\text { (ng/L) }\end{array}$ & $\begin{array}{l}\text { DF } \\
(\%)\end{array}$ & Region & Reference \\
\hline \multirow[t]{3}{*}{ AMP } & $<\mathrm{MQL}$ & $<\mathrm{MQL}$ & 0 & $<\mathrm{MQL}-11$ & 3 & USA & (Cha et al., 2006) \\
\hline & & & & $21-184$ & 100 & Ghana & (Azanu et al., 2018) \\
\hline & & & & $3,211-5,509$ & 100 & South Africa & (Agunbiade and Moodley, 2016) \\
\hline \multirow[t]{6}{*}{ AMX } & $<$ MQL-1,126 & $<\mathrm{MQL}$ & 24 & $1.9-25.2$ & 100 & Italy & (Riva et al., 2019) \\
\hline & & & & $<\mathrm{MQL}$ & 0 & Singapore & (Tran et al., 2016b) \\
\hline & & & & $<\mathrm{MQL}-68$ & $<100$ & France & (Dinh et al., 2011) \\
\hline & & & & $<10-622$ & $0-100$ & UK & (Kasprzyk-Hordern et al., 2008) \\
\hline & & & & $<\mathrm{MQL}-200$ & 30 & Australia & (Watkinson et al., 2009) \\
\hline & & & & $<\mathrm{MQL}-2.7$ & $<100$ & Ghana & (Azanu et al., 2018) \\
\hline \multirow[t]{6}{*}{ AZT } & $4-89$ & 11 & 100 & $0.2-79.2$ & 100 & Singapore & (Tran et al., 2016b) \\
\hline & & & & $<\mathrm{MQL}$ & 0 & Iran & (Mirzaei et al., 2018) \\
\hline & & & & $10-3,400$ & 100 & Croatia & (Bielen et al., 2017) \\
\hline & & & & $<$ MQL-115.5 & $<100$ & Spain & (Rodriguez-Mozaz et al., 2015) \\
\hline & & & & $<$ MQL-8.6 & & Pakistan & (Khan et al., 2013) \\
\hline & & & & $<$ MQL-67 & 83 & China & (Zhou et al., 2016) \\
\hline \multirow[t]{4}{*}{ CAP } & $<\mathrm{MQL}-22$ & 6 & 68 & $<$ MQL-8.0 & $<100$ & Singapore & (Tran et al., 2016b) \\
\hline & & & & $<\mathrm{MQL}-60$ & 7.7 & Germany & (Hirsch et al., 1999) \\
\hline & & & & $4.2-28.4$ & 100 & China & (Jiang et al., 2011) \\
\hline & & & & $<\mathrm{MQL}-53.8$ & $<100$ & Korea & (Choi et al., 2008) \\
\hline CEFX & $<\mathrm{MQL}$ & $<\mathrm{MQL}$ & 0 & $<\mathrm{MQL}-136.31$ & $<100$ & Germany & (Mirzaei et al., 2017) \\
\hline CFZ & $<\mathrm{MQL}$ & $<\mathrm{MQL}$ & 0 & $<\mathrm{MQL}$ & 0 & Singapore & (Tran et al., 2016b) \\
\hline \multirow[t]{9}{*}{ CIPX } & $<$ MQL-115 & 11 & 56 & $<\mathrm{MQL}$ & 0 & Singapore & (Tran et al., 2016b) \\
\hline & & & & & 100 & Spain & (Rodriguez-Mozaz et al., 2015) \\
\hline & & & & $17^{\mathrm{a}-34}$ & - & Africa & (aus der Beek et al., 2016) \\
\hline & & & & $61,940^{a}-65 \times 10^{5}$ & - & Asia-Pacific & (aus der Beek et al., 2016) \\
\hline & & & & $2^{\mathrm{a}}-13,600$ & - & Europe & (aus der Beek et al., 2016) \\
\hline & & & & $<$ MQL-1,300 & 30 & Australia & (Watkinson et al., 2009) \\
\hline & & & & $<$ MQL-135 & $<100$ & France & (Dinh et al., 2011) \\
\hline & & & & $3.56-24.8$ & 100 & China & (Zhang et al., 2014) \\
\hline & & & & $<\mathrm{MQL}-110$ & $<100$ & Pakistan & (Khan et al., 2013) \\
\hline \multirow[t]{5}{*}{ CLAR } & $4-65$ & 16 & 100 & $0.05-55.42$ & 100 & Singapore & (Tran et al., 2016b) \\
\hline & & & & $35.4-96.3$ & 100 & Spain & (Rodriguez-Mozaz et al., 2015) \\
\hline & & & & $<\mathrm{MQL}-48$ & 93 & China & (Zhou et al., 2016) \\
\hline & & & & $<\mathrm{MQL}-260$ & 21.2 & Germany & (Hirsch et al., 1999) \\
\hline & & & & $0.5-130$ & 100 & Pakistan & (Khan et al., 2013) \\
\hline
\end{tabular}


Table 3. Continued.

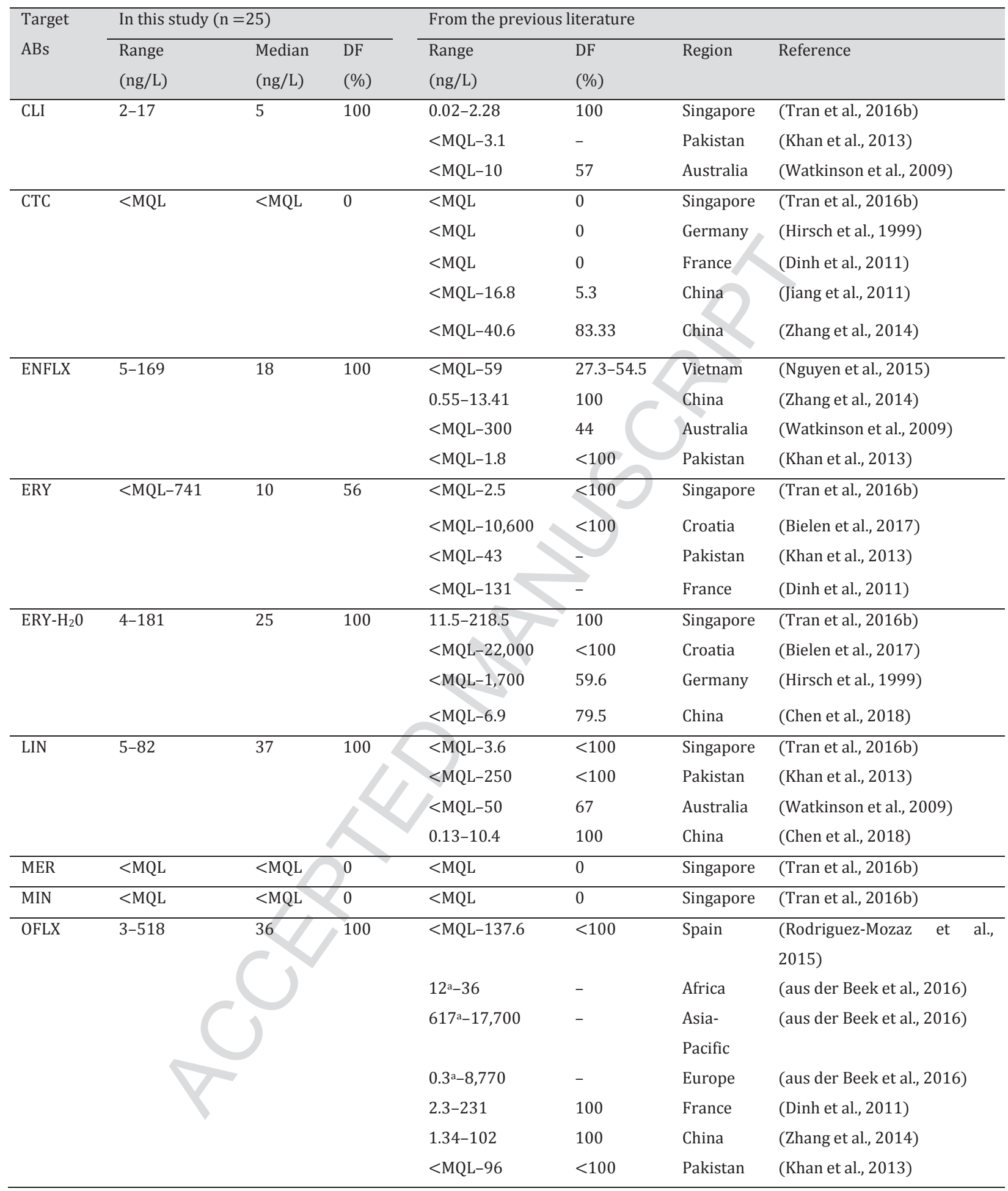


Table 3. Continued.

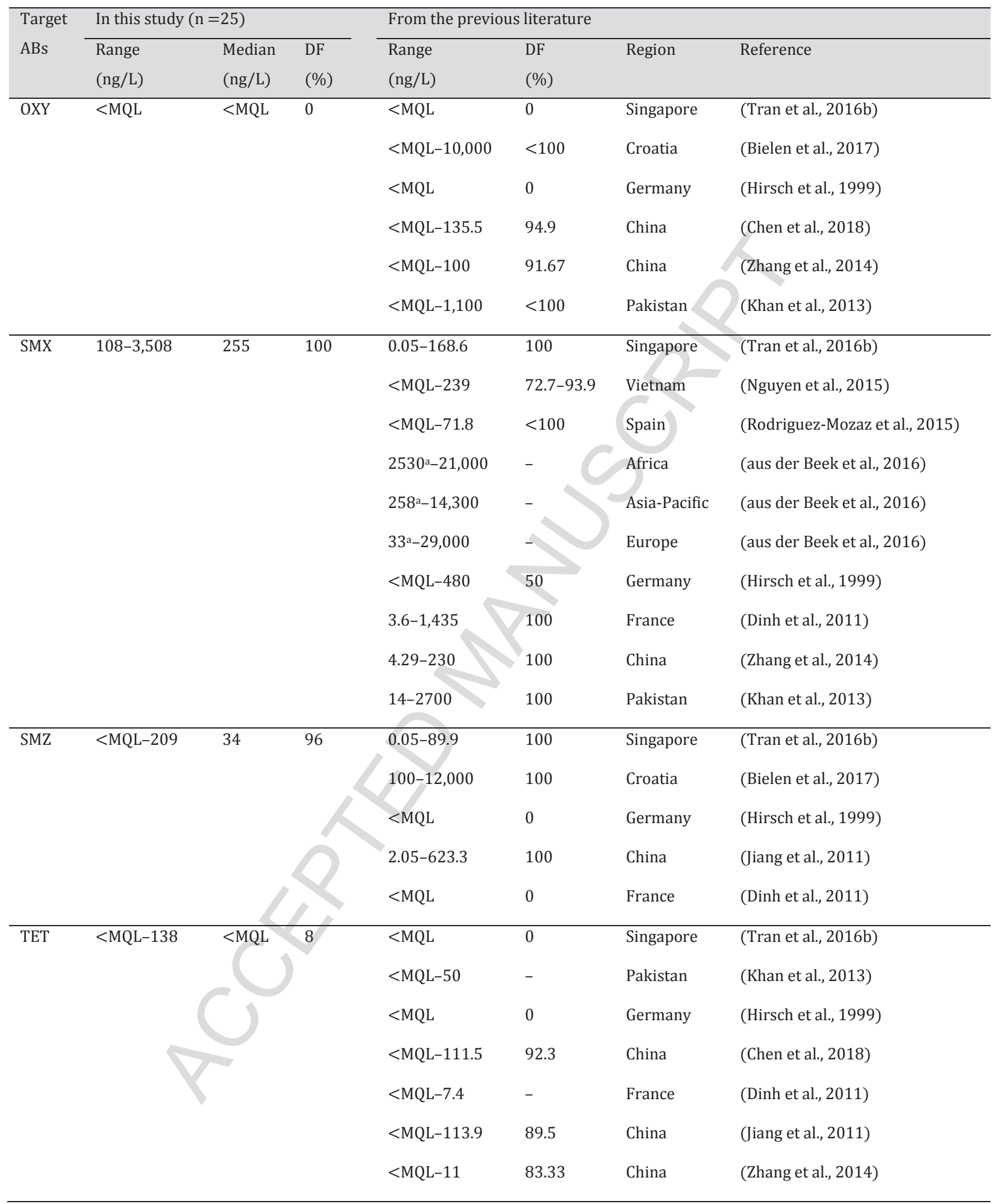


Table 3. Continued.

\begin{tabular}{|c|c|c|c|c|c|c|c|}
\hline Target & In this stud & 25) & & From the prev & is literature & & \\
\hline $\mathrm{ABs}$ & $\begin{array}{l}\text { Range } \\
\text { (ng/L) }\end{array}$ & $\begin{array}{l}\text { Median } \\
\text { (ng/L) }\end{array}$ & $\begin{array}{l}\text { DF } \\
(\%)\end{array}$ & $\begin{array}{l}\text { Range } \\
\text { (ng/L) }\end{array}$ & $\begin{array}{l}\text { DF } \\
(\%)\end{array}$ & Region & Reference \\
\hline TMP & $2-70$ & 26 & 100 & $\begin{array}{l}<\text { MQL-96.4 } \\
<\text { MQL-330 } \\
<\text { MQL-1,100 } \\
<\text { MQL-92.7 } \\
985^{\mathrm{a}-5,500} \\
128^{\mathrm{a}-13,600} \\
12^{\mathrm{a}-10,000} \\
<\mathrm{MQL}-130 \\
3-26\end{array}$ & $\begin{array}{l}0 \\
74.1-100 \\
<100 \\
<100 \\
- \\
- \\
- \\
30 \\
100\end{array}$ & $\begin{array}{l}\text { Spain } \\
\text { Africa } \\
\text { Asia-Pacifi } \\
\text { Europe } \\
\text { Australia } \\
\text { China }\end{array}$ & $\begin{array}{l}\text { (Tran et al., 2016b) } \\
\text { (Nguyen et al., 2015) } \\
\text { (Bielen et al., 2017) } \\
\text { (Rodriguez-Mozaz et al., 2015) } \\
\text { (aus der Beek et al., 2016) } \\
\text { (aus der Beek et al., 2016) } \\
\text { (aus der Beek et al., 2016) } \\
\text { (Watkinson et al., 2009) } \\
\text { (Zhou et al., 2016) }\end{array}$ \\
\hline TYL & $<\mathrm{MQL}-47$ & $<\mathrm{MQL}$ & 24 & $\begin{array}{l}<\mathrm{MQL} \\
<\mathrm{MQL}-1.6 \\
<\mathrm{MQL}-0.61 \\
<\mathrm{MQL}-2.8 \\
<\mathrm{MQL}-60 \\
<\mathrm{MQL}-15\end{array}$ & $\begin{array}{l}0 \\
74.4 \\
63.2 \\
<100 \\
81 \\
<100\end{array}$ & $\begin{array}{l}\text { Singapore } \\
\text { China } \\
\text { China } \\
\text { France } \\
\text { Australia } \\
\text { Germany }\end{array}$ & $\begin{array}{l}\text { (Tran et al., 2016b) } \\
\text { (Chen et al., 2018) } \\
\text { (Jiang et al., 2011) } \\
\text { (Dinh et al., 2011) } \\
\text { (Watkinson et al., 2009) } \\
\text { (Burke et al., 2016) }\end{array}$ \\
\hline VCM & $<\mathrm{MQL}-26$ & 12 & 52 & $<\mathrm{MQL}$ & $\begin{array}{l}0 \\
<100\end{array}$ & $\begin{array}{l}\text { Singapore } \\
\text { France }\end{array}$ & $\begin{array}{l}\text { (Tran et al., 2016b) } \\
\text { (Dinh et al., 2011) }\end{array}$ \\
\hline
\end{tabular}

a: average concentration; DF: detection frequency; MQL: method quantification limit; -: not reported. 
Table 4. Predicted no-effect concentrations (PNECARM) for antibiotic resistance development.

\begin{tabular}{|c|c|c|c|}
\hline \multirow[t]{2}{*}{ Target antibiotics } & \multicolumn{2}{|c|}{ Collected from the literature } & \multirow{2}{*}{$\begin{array}{l}\text { To be used in this study } \\
\text { Lowest PNEC }_{\text {AMR }}(\mathrm{ng} / \mathrm{L})\end{array}$} \\
\hline & $\mathrm{PNEC}_{\mathrm{AMR}}(\mathrm{ng} / \mathrm{L})$ & Reference & \\
\hline \multirow[t]{2}{*}{ AMP } & 75 & (Kümmerer and Henninger, 2003) & 75 \\
\hline & 250 & (Bengtsson-Palme and Larsson, 2016) & \\
\hline \multirow[t]{2}{*}{ AMX } & 100 & (Kümmerer and Henninger, 2003) & 100 \\
\hline & 250 & (Bengtsson-Palme and Larsson, 2016) & \\
\hline \multirow[t]{2}{*}{ AZT } & 150 & (Kümmerer and Henninger, 2003) & 150 \\
\hline & 250 & (Bengtsson-Palme and Larsson, 2016) & \\
\hline \multirow[t]{2}{*}{ CAP } & 1600 & (Kümmerer and Henninger, 2003) & 1600 \\
\hline & 8000 & (Bengtsson-Palme and Larsson, 2016) & \\
\hline \multirow[t]{2}{*}{ CEFX } & 40 & (Kümmerer and Henninger, 2003) & 40 \\
\hline & 64 & (Bengtsson-Palme and Larsson, 2016) & \\
\hline \multirow[t]{2}{*}{ CFZ } & 100 & (Kümmerer and Henninger, 2003) & 100 \\
\hline & 500 & (Bengtsson-Palme and Larsson, 2016) & \\
\hline \multirow[t]{2}{*}{ CIPX } & 20 & (Kümmerer and Henninger, 2003) & 20 \\
\hline & 64 & (Bengtsson-Palme and Larsson, 2016) & \\
\hline \multirow[t]{2}{*}{ CLAR } & 40 & (Kümmerer and Henninger, 2003) & 40 \\
\hline & 250 & (Bengtsson-Palme and Larsson, 2016) & \\
\hline \multirow[t]{2}{*}{ CLI } & 500 & (Kümmerer and Henninger, 2003) & 500 \\
\hline & 1000 & (Bengtsson-Palme and Larsson, 2016) & \\
\hline CTC & n.r & n.r & n.r \\
\hline ENFLX & 64 & (Bengtsson-Palme and Larsson, 2016) & 64 \\
\hline \multirow[t]{2}{*}{ ERY } & 40 & (Kümmerer and Henninger, 2003) & 40 \\
\hline & 1000 & (Bengtsson-Palme and Larsson, 2016) & \\
\hline $\mathrm{ERY}-\mathrm{H}_{2} \mathrm{O}$ & n.r & n.r & n.r \\
\hline LIN & 2000 & (Bengtsson-Palme and Larsson, 2016) & 2000 \\
\hline \multirow[t]{2}{*}{ MER } & 80 & (Kümmerer and Henninger, 2003) & 64 \\
\hline & 64 & (Bengtsson-Palme and Larsson, 2016) & \\
\hline \multirow[t]{2}{*}{ MIN } & 300 & (Kümmerer and Henninger, 2003) & 300 \\
\hline & 1000 & (Bengtsson-Palme and Larsson, 2016) & \\
\hline \multirow[t]{2}{*}{ OFLX } & 40 & (Kümmerer and Henninger, 2003) & 40 \\
\hline & 500 & (Bengtsson-Palme and Larsson, 2016) & \\
\hline OXY & 500 & (Bengtsson-Palme and Larsson, 2016) & 500 \\
\hline \multirow[t]{2}{*}{ SMX } & 20,000 & (Kümmerer and Henninger, 2003) & 16,000 \\
\hline & 16,000 & (Bengtsson-Palme and Larsson, 2016) & \\
\hline SMZ & n.r & n.r & n.r \\
\hline \multirow[t]{2}{*}{ TET } & 300 & (Kümmerer and Henninger, 2003) & 300 \\
\hline & 1000 & (Bengtsson-Palme and Larsson, 2016) & \\
\hline \multirow[t]{2}{*}{ TMP } & 1,000 & (Kümmerer and Henninger, 2003) & 500 \\
\hline & 500 & (Bengtsson-Palme and Larsson, 2016) & \\
\hline TYL & 4000 & (Bengtsson-Palme and Larsson, 2016) & 4000 \\
\hline \multirow[t]{2}{*}{ VCM } & 600 & (Kümmerer and Henninger, 2003) & 600 \\
\hline & 8000 & (Bengtsson-Palme and Larsson, 2016) & \\
\hline
\end{tabular}

PNEC $_{\mathrm{AMR}}$ : predicted no-effect concentrations for resistance selection/development; -: not calculated; n.r: not reported. 


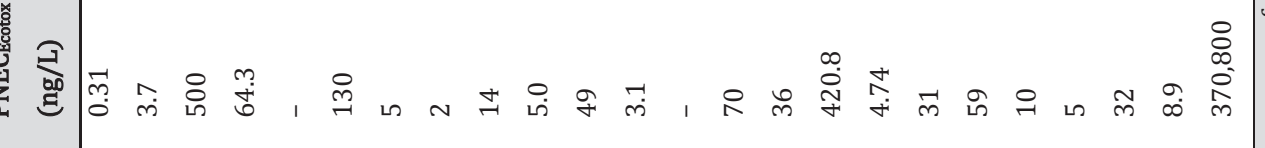

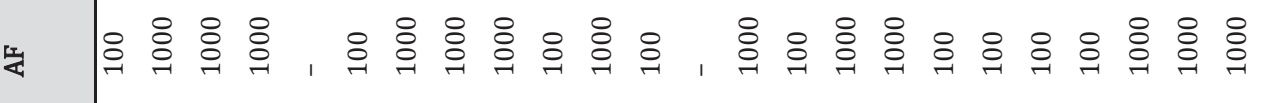

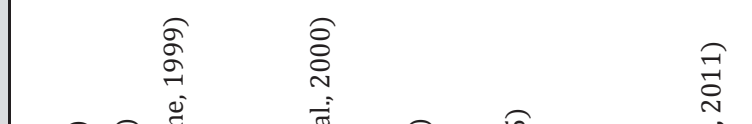

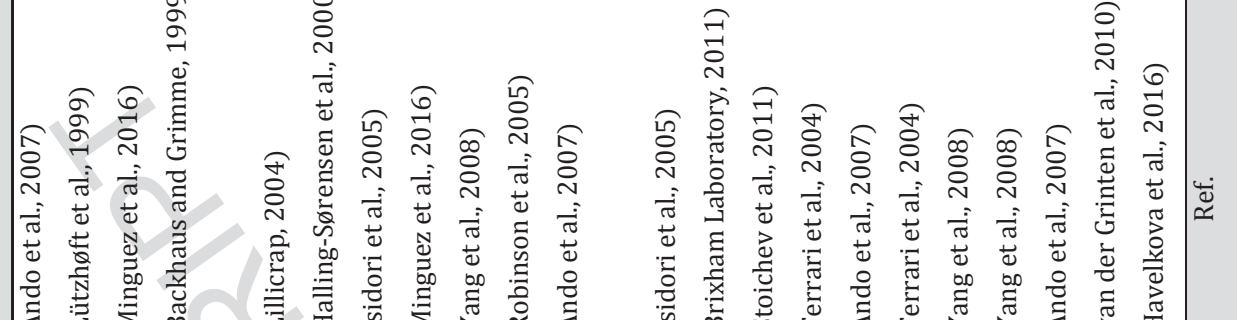

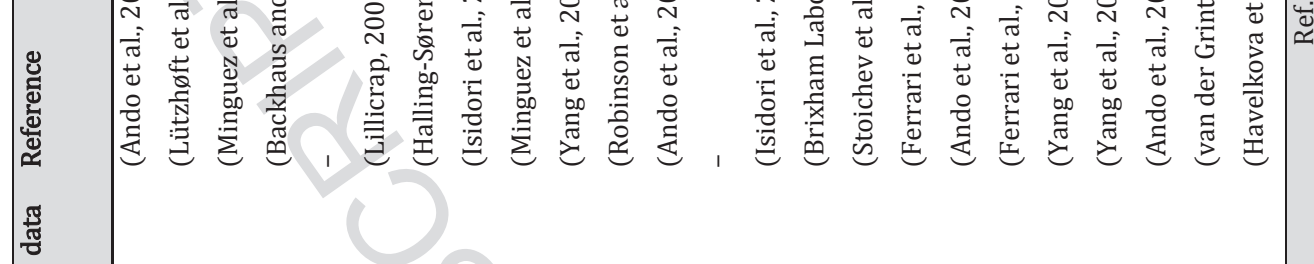

త్ర

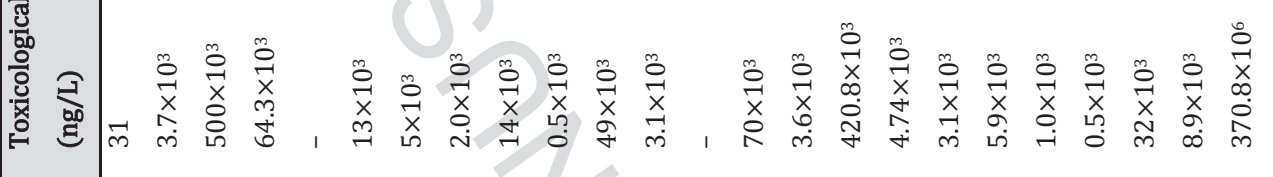

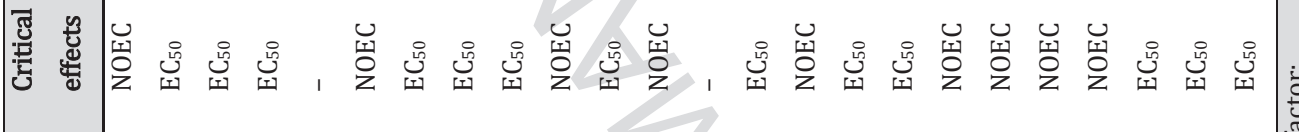

气

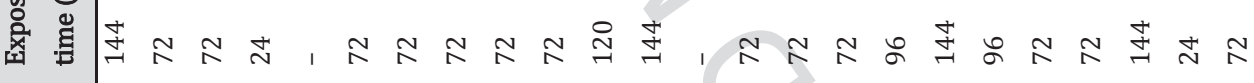

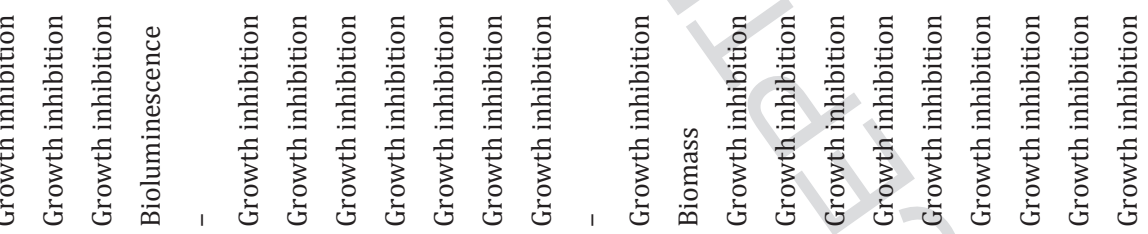

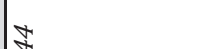

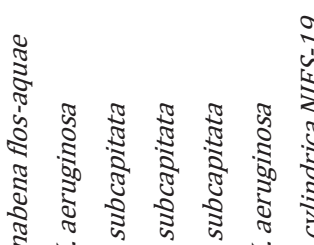

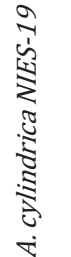

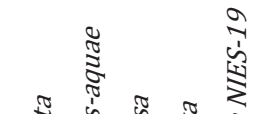

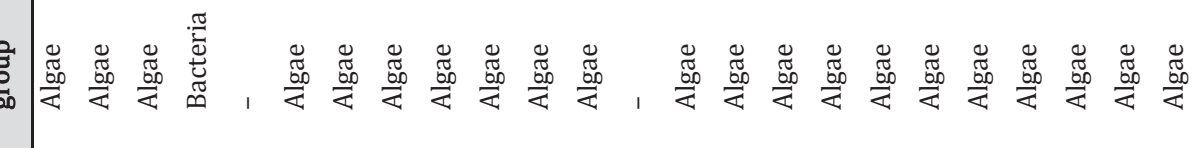

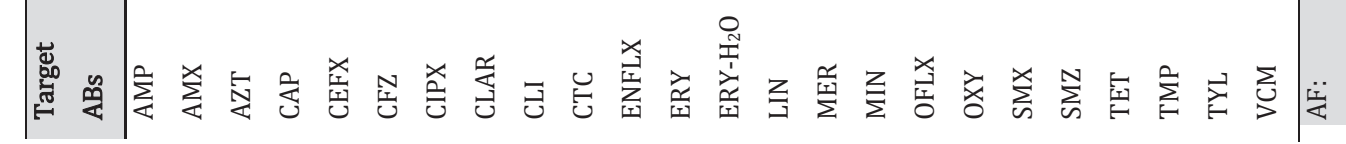




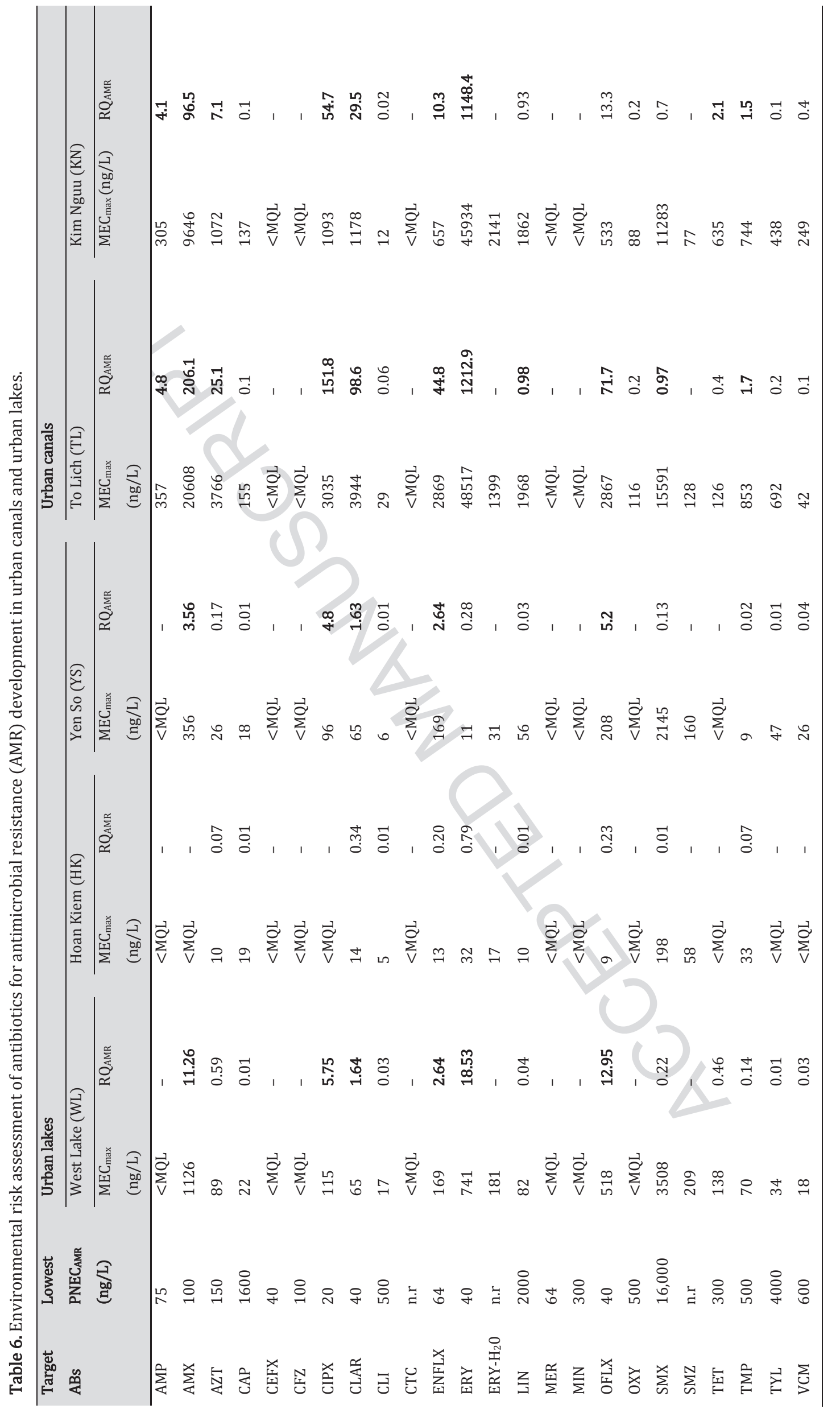

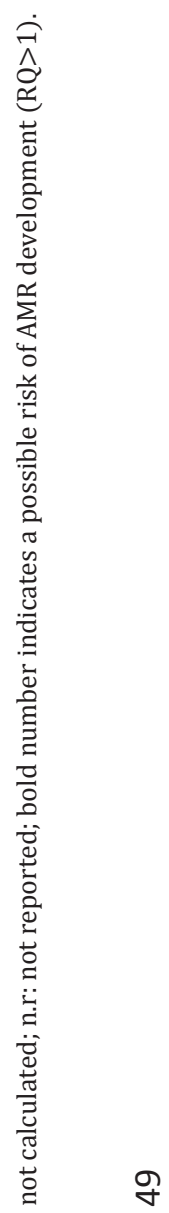




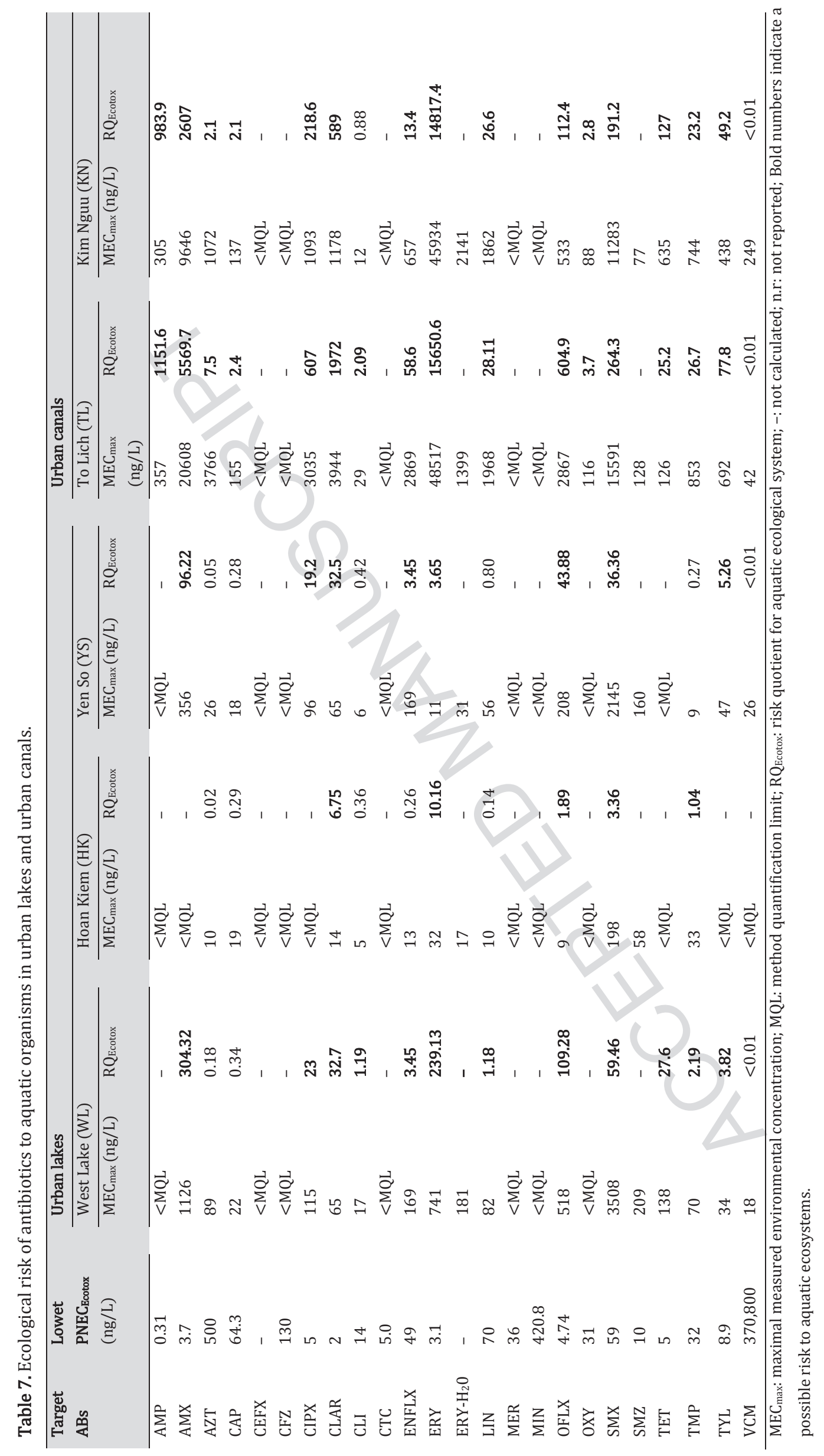




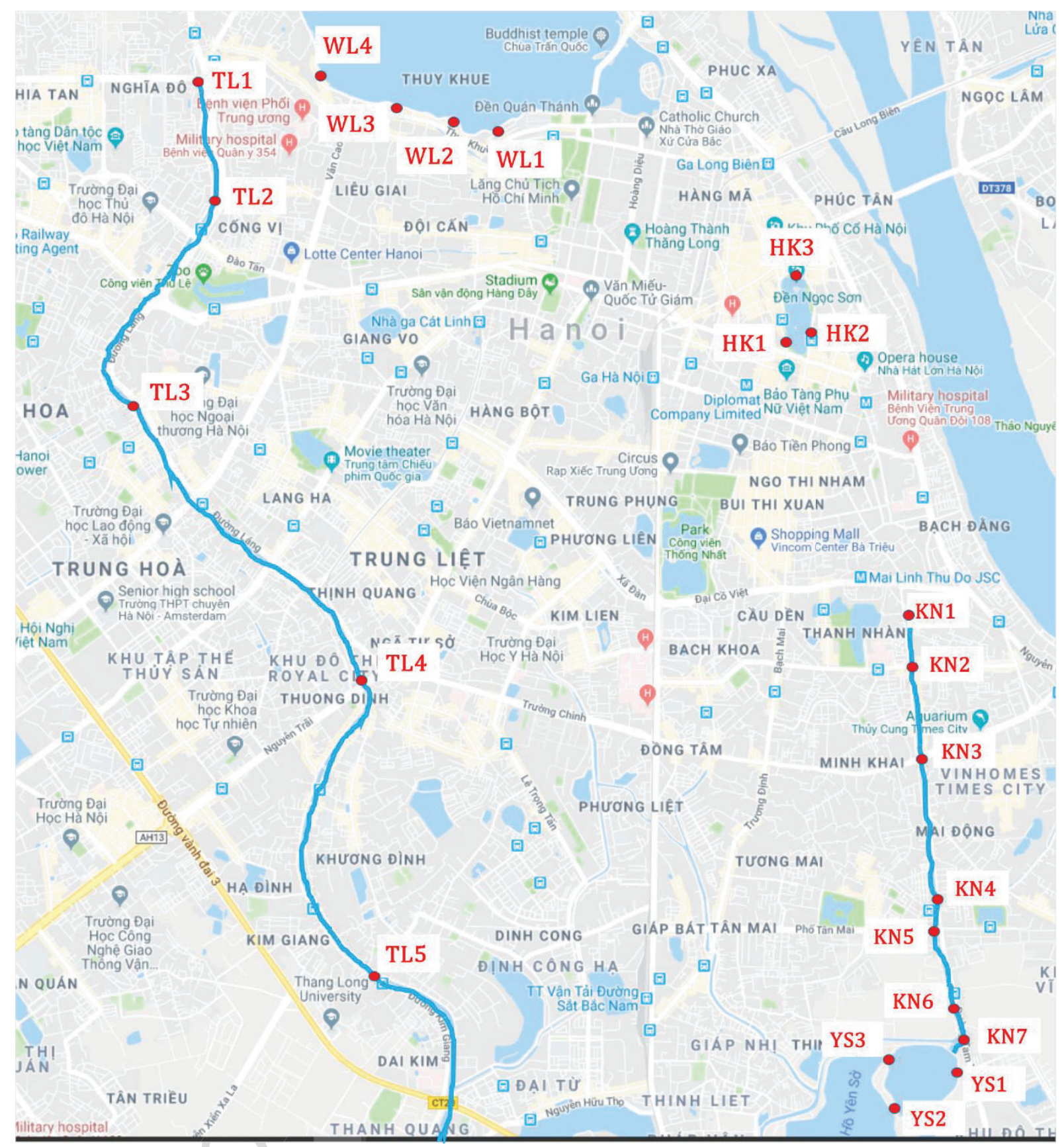

Fig. 1. Sampling map for two urban canals and three urban lakes. Sampling points TL1-TL5 are located in To Lich (TL) canal; KN1-KN7 are situated in Kim Nguu (KN) canal; sampling points WL1-WL4 are located in West Lake (WL); sampling points HK1-HK3 are situated in Hoan Kiem (HK) lake; sampling points YS1-YS3 are located in Yen So (YS) lake. 

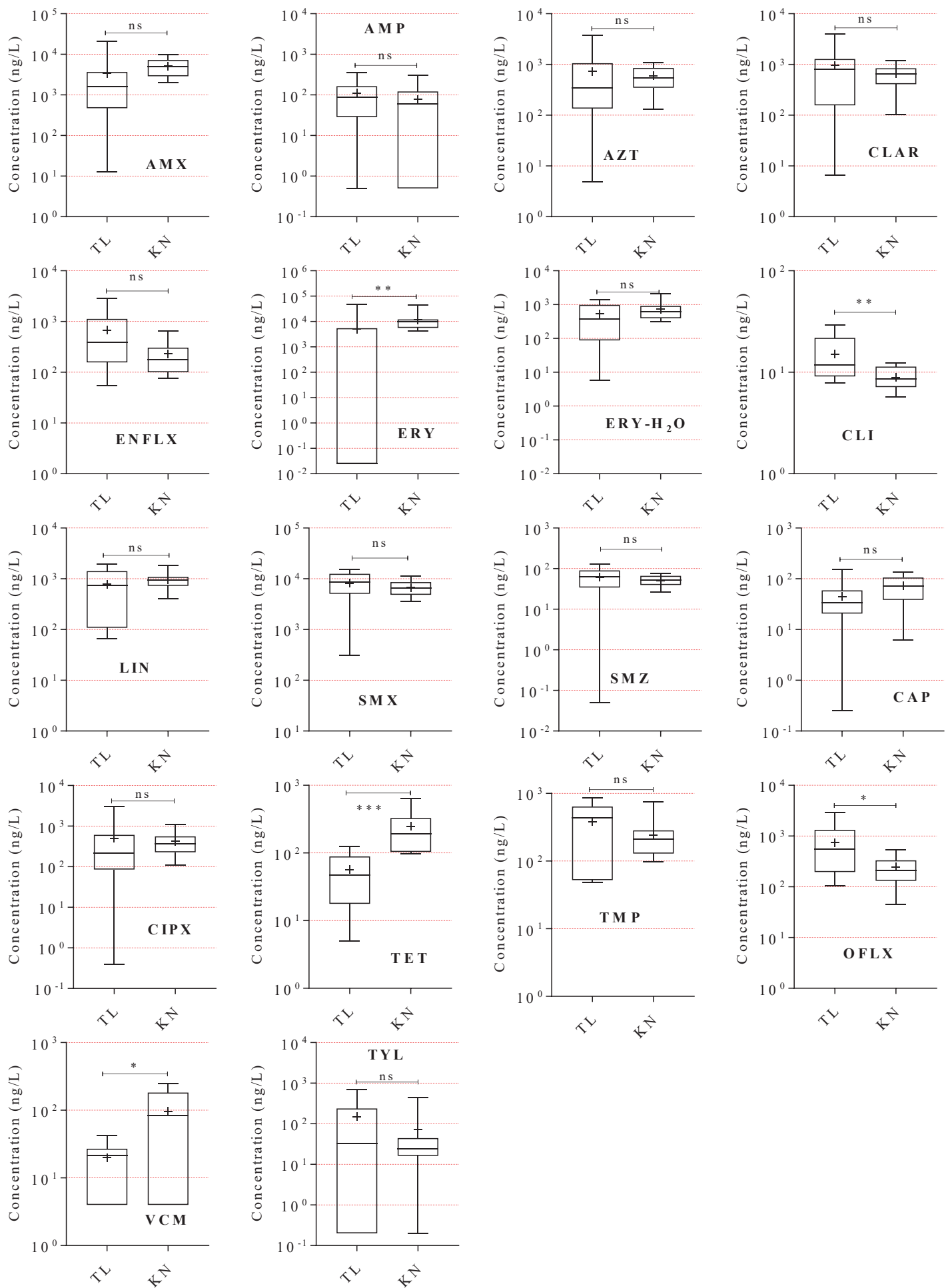

Fig. 2. Box-and-whisker plots showing the concentrations of detected antibiotics in the two urban canals, To Lich (TL, $\mathrm{n}=14)$ and Kim Nguu $(\mathrm{KN}, \mathrm{n}=14)$. Levels of significance of $p<0.05\left(^{*}\right), p<0.01(* *), p<0.001\left(^{* * *}\right) ; p>0.05$ indicates no significant difference (ns). 

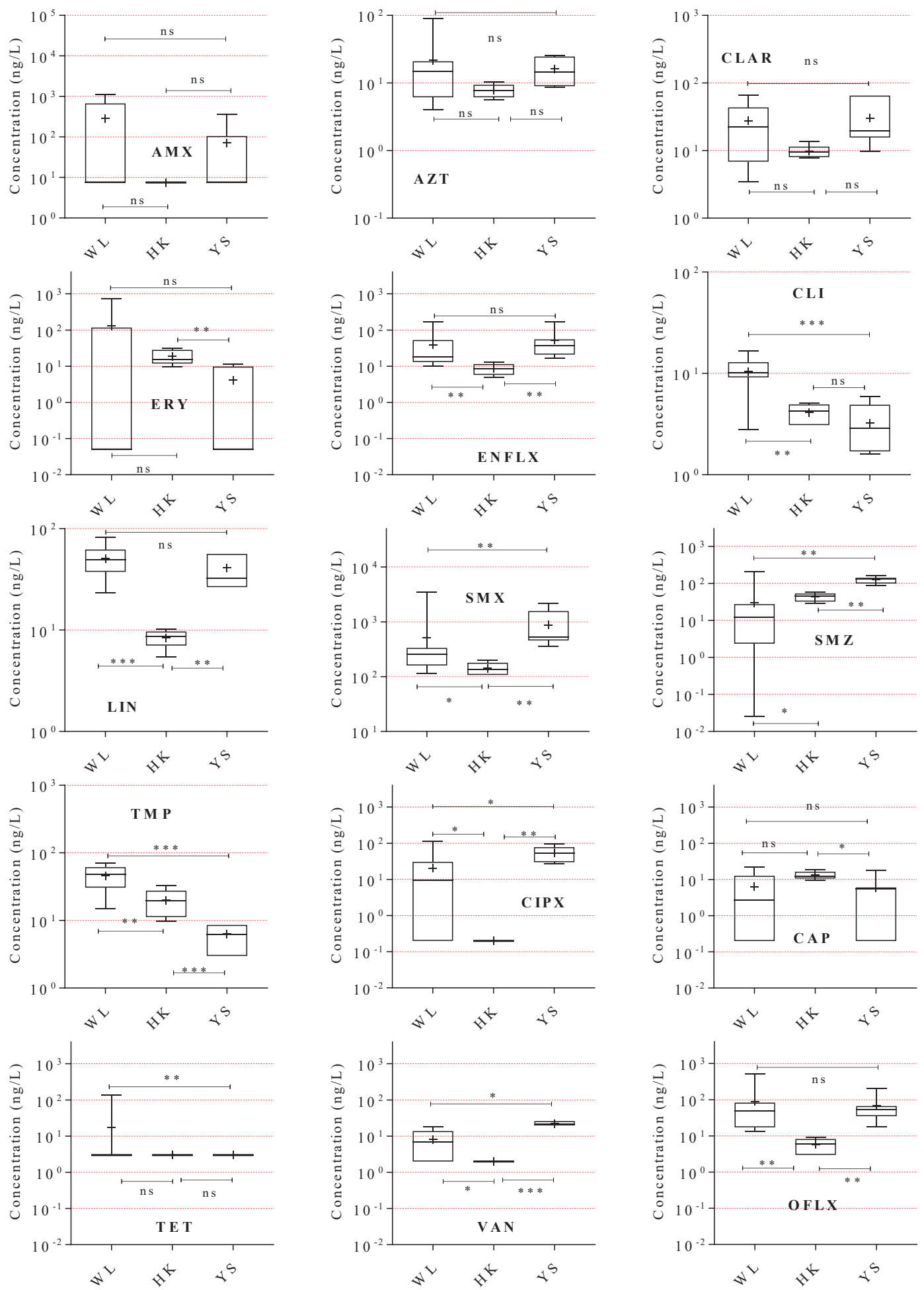

Fig. 3. Box-and-whisker plots showing the concentrations of detected antibiotics in the three urban lakes, West Lake $(\mathrm{WL}, \mathrm{n}=12)$, Hoan Kiem (HK, $\mathrm{n}=6)$, and Yen So (YS, $\mathrm{n}=7)$. Levels of significance of $p<0.05\left(^{*}\right), p<0.01(* *), p<0.001$ $(* *) ; p>0.05$ indicates no significant difference (ns). 